\title{
Comparison of land surface emissivity and radiometric temperature derived from MODIS and ASTER sensors
}

Frédéric Jacob ${ }^{\mathrm{a}, \mathrm{b}, *}$, François Petitcolin $^{\mathrm{c}}$, Thomas Schmugge ${ }^{\mathrm{a}}$, Éric Vermote ${ }^{\mathrm{d}}$, Andrew French ${ }^{\mathrm{e}}$, Kenta Ogawa ${ }^{\mathrm{a}}$

${ }^{a}$ USDA / ARS / Hydrology and Remote Sensing Laboratory, Bldg 007, BARC-West, Beltsville, MD 20705, USA

${ }^{\mathrm{b}}$ PURPAN - école supérieure d'agriculture, Département Sciences et Méthodes, Laboratoire de Télédétection et de Gestion des Territoires, 75, voie du TOEC, 31076 TOULOUSE Cedex 3, France

${ }^{\mathrm{c}} A C R I-S T$,

260, route du Pin Montard, B.P. 234, 06904 SOPHIA ANTIPOLIS Cedex, France

${ }^{\mathrm{d}}$ University of Maryland / Dept of Geography and NASA / GSFC, Bldg 32, Room S36D, NASA / GSFC Code 923, Greenbelt, MD 20771, USA

${ }^{\mathrm{e}}$ National Research Council Associateship, NASA / GSFC / Hydrological Sciences Branch, Code 974.1, Greenbelt, MD 20771, USA 


\begin{abstract}
This study compared surface emissivity and radiometric temperature retrievals derived from data collected with the MODerate resolution Imaging Spectroradiometer (MODIS) and Advanced Spaceborne Thermal Emission Reflection Radiometer (ASTER) sensors, onboard the NASA's Earth Observation System (EOS) - TERRA satellite. Two study sites were selected: a semi-arid area located in northern Chihuahuan desert, USA, and a Savannah landscape located in central Africa. Atmospheric corrections were performed using the MODTRAN 4 atmospheric radiative transfer code along with atmospheric profiles generated by the National Center for Environmental Predictions (NCEP). Atmospheric radiative properties were derived from MODTRAN 4 calculations according to the sensor swaths, which yielded different strategies from one sensor to the other. The MODIS estimates were then computed using a designed Temperature Independent Spectral Indices of Emissivity (TISIE) method. The ASTER estimates were derived using the Temperature Emissivity Separation (TES) algorithm. The MODIS and ASTER radiometric temperature retrievals were in good agreement when the atmospheric corrections were similar, with differences lower than $0.9 \mathrm{~K}$. The emissivity estimates were compared for MODIS / ASTER matching bands at 8.5 and $11 \mu \mathrm{m}$. It was shown that the retrievals agreed well, with RMSD ranging from 0.005 to 0.015 , and biases ranging from -0.01 to 0.005 . At $8.5 \mu \mathrm{m}$, the ranges of emissivities from both sensors were very similar. At $11 \mu \mathrm{m}$, however, the ranges of MODIS values were broader than those of the ASTER estimates. The larger MODIS values were ascribed to the gray body problem of the TES algorithm, whereas the lower MODIS values were not consistent with field references. Finally, we assessed the combined effects of spatial variability and sensor resolution. It was shown that for the study areas we considered, these effects were not critical.
\end{abstract}

Key words: MIR / TIR remote sensing, surface emissivity and radiometric temperature, MODIS, ASTER, TISIE, TES, atmospheric corrections, spatial variability.

* Corresponding author. Phone: 33(0)56-115-2961, Fax: 33(0)56-115-3060

Email address: frederic . jacob@esa-purpan. fr (Frédéric Jacob). 


\section{Contents}

1 Introduction 4

2 Material and methods 8

2.1 The sensors $\quad 8$

2.2 The MODIS / TISIE and ASTER / TES algorithms 10

$\begin{array}{lll}2.3 & \text { Data set: description and preprocessing } & 16\end{array}$

3 Results and discussion $\quad 22$

3.1 Comparing brightness temperature at the sensor level 22

3.2 Comparing brightness temperature at the surface level 24

3.3 Comparing surface emissivity and radiometric temperature 27

3.4 Assessing the combined effects of surface heterogeneity and spatial resolution

4 Conclusion $\quad 32$ 


\section{$1 \quad 1$ Introduction}

2 Knowledge of land surface temperature and broadband emissivity is of prime inter-

3 est when studying energy and water balance of Earth, biosphere and atmosphere.

4 Surface temperature is a key variable when dealing with exchanges between bio-

5 sphere and atmosphere since it drives heat transfers at the surface - atmosphere in-

6 terface (Schmugge et al., 1998b; Schmugge and Kustas, 1999; Olioso et al., 1999,

7 2002; Jacob et al., 2002). Surface broadband emissivity is a key variable when

8 dealing with the Earth's radiation budget since it drives the surface longwave ra-

9 diative balance (Ogawa et al., 2003; Zhou et al., 2003). Thermal InfraRed (TIR)

10 remote sensing provides the unique possibility to retrieve surface temperature and

11 broadband emissivity in a spatially distributed manner. Surface temperature can be

12 derived from the channel radiances by estimating the channel emissivities (see the

13 review by Dash et al. (2002)). Surface broadband emissivity can be estimated as

14 a linear combination of the channel estimates (Ogawa et al., 2002, 2003). Surface

15 emissivity is defined as the ratio of the actual radiance emitted by a given surface to

16 that emitted by a blackbody at the same thermodynamic (or kinetic) temperature.

17 When dealing with remote sensing over heterogeneous land surfaces which display

18 non uniform distributions of temperature, the variables of interest are ensemble

19 emissivity and radiometric temperature (Norman and Becker, 1995). Radiometric

temperature is then equal to kinetic temperature for a homogeneous and isothermal

surface (Becker and Li, 1995). However, surface heterogeneities induce non linear

22

effects that can affect the validity of the assumptions made to retrieve emissivity 
1 and radiometric temperature. This may be a critical issue since natural landscapes

2 can display significant spatial variability of emissivity (Ogawa et al., 2002).

3 Among the several sensors on board the NASA's Earth Observation System (EOS)

4 TERRA (formerly EOS - AM1) platform that was launched in 1999, the Advanced

5 Spaceborne Thermal Emission Reflection Radiometer (ASTER) and MODerate

6 resolution Imaging Spectroradiometer (MODIS) instruments were designed to pro-

7 vide high quality observations of land surfaces, atmosphere and oceans. ASTER

8 was designed to collect data over shortwave and longwave infrared domains for ge-

9 ological applications (Yamaguchi et al., 1998). Therefore, its spectral features were

10 set to provide a good sampling of the TIR emissivity spectral variations. Another

11 important objective was acquiring high spatial resolution data to study upscaling

12 processes which occur when considering coarser resolutions, i.e. non linear effects

13 induced by the use of models designed for homogeneous surfaces over heteroge-

14 neous pixels. MODIS was designed to collect, at a moderate spatial resolution (i.e.

15 kilometer resolution), multiangular observations over a wide spectral range, with

16 almost daily coverage of the Earth (Justice et al., 1998). Therefore, the sensor pro-

17 vides multitemporal and multidirectional remotely sensed data within several spec-

18 tral bands over the Middle InfraRed (MIR) and TIR domains.

19 Several algorithms have been developed these two last decades to accurately estimate surface emissivity and radiometric temperature, with the goal to reach an accuracy ranging between 0.8 and $1 \mathrm{~K}$ for surface temperature (Seguin et al., 1999).

22 These algorithms rely on methods which use the available information according 
1 to the spectral, directional and temporal features of the considered sensors. Two

2 widely accepted approaches are the Temperature Emissivity Separation (TES) algo-

3 rithm (Gillespie et al., 1996, 1998; Schmugge et al., 1998a, 2002a), and the Temper-

4 ature Independent Spectral Indices of Emissivity (TISIE) approach (Becker and Li,

5 1990; Li and Becker, 1993; Nerry et al., 1998; Petitcolin et al., 2002a,b; Petitcolin

6 and Vermote, 2002). TES was developed for the spectral features of ASTER which

7 yield single temporal and mono directional observations within several spectral

8 bands over the TIR domain. TISIE was developed to use the information provided

9 by multidirectional and multitemporal MIR / TIR data, such as those collected by

10 MODIS. The performances of the TES algorithm were theoretically and experi-

11 mentally assessed by Gillespie et al. (1996, 1998), and Schmugge et al. (1998a,

12 2002a). The performances of the TISIE algorithm were analyzed by Nerry et al.

13 (1998), Petitcolin et al. (2002a,b) and Petitcolin and Vermote (2002). The results

14 reported by these studies yielded accuracies around 0.01 and $1 \mathrm{~K}$ for surface emis-

15 sivity and radiometric temperature, respectively.

16 In this study, we proposed to compare ASTER and MODIS emissivity / radiomet-

17 ric temperature estimates derived from the TES and TISIE algorithms designed by Schmugge et al. (1998a) and Petitcolin and Vermote (2002), respectively. Per-

forming such a comparison was of interest for several reasons. First, the considered algorithms relied on different assumptions according to the temporal, directional and spectral information provided by each sensor. Consequently, considering nu-

merous environmental situations depicted by MODIS / ASTER scenes, a compar-

ison of the TES and TISIE retrievals allowed assessing the consistency between 
the algorithms. ASTER and MODIS are on the same platform, which provides the opportunity to perform such a comparison for the first time. Indeed, acquisition time is critical for TIR observations because of the non stable nature of the kinetic temperature. Therefore, comparing algorithm retrievals was unique and provided complementary investigations to validation studies which require much effort to account for numerous environmental situations. Once the consistency between the algorithms was shown, the second interest of this comparison was the possibility to assess problems related to upscaling issues such as non linear effects induced by spatial heterogeneity. Since algorithms devoted to the retrieval of surface radiometric temperature and emissivity are generally based on non linear equation systems, their application over heterogeneous areas introduces a dependence on spatial resolution. Indeed, averaging algorithm outputs or running algorithms on averaged inputs may provide results which significantly differ. This is a critical issue for further investigations based on knowledge of surface radiometric temperature and emissivity, such as estimating Earth's radiation budget or energetic exchanges at the surface - atmosphere interface using kilometric resolution sensors.

In this paper, we considered two sets of MODIS / ASTER scenes collected over two areas. The first area was located in the Central African Republic; and the second area was located in northern Chihuahuan desert, New Mexico, USA. This yields a data set which included numerous land use situations: Savannah landscape, semiarid rangelands, mountainous areas, irrigated agricultural areas and gypsum sand dunes. Atmospheric corrections were performed using the MODTRAN 4 radiative transfer model (Berk et al., 1998) along with atmospheric profiles provided by the 
1 National Center for Environmental Prediction (NCEP). In order to minimize the discrepancies between MODIS / TISIE and ASTER / TES retrievals due to factors 3 other than the algorithm differences, we used the same atmospheric profiles for

4 both sensors when characterizing atmosphere state for MODTRAN 4 calculations.

5 Next, ASTER and MODIS surface emissivity / radiometric temperature were com-

6 puted using the TES and TISIE algorithms, respectively. For a better understanding

7 of possible differences between the MODIS and ASTER retrievals because of the 8 experimental context (sensor instrumental features, magnitude of the atmospheric 9 corrections, land use occupation), we first compared intermediate variables such as 10 brightness temperature at the sensor and ground levels. Brightness temperatures and 11 emissivities were compared for the ASTER / MODIS matching bands at 8.6 and $1211 \mu \mathrm{m}$ (see Figure 1). Finally, we assessed the combined effects of spatial variabil13 ity and sensor resolution. This was performed intercomparing ASTER and MODIS retrievals of surface radiometric temperature for different levels of spatial variabil15 ity of the ASTER aggregated values inside MODIS pixels. After the description of 16 the sensors and the corresponding algorithms, we describe the data preprocessing, 17 and next report the comparison results.

\section{Material and methods}

\section{$19 \quad 2.1$ The sensors}

Both ASTER and MODIS are on EOS - TERRA, a sun-synchronous platform with 21 a 10:30 am descending equator crossing. The ASTER TIR sensor is a five band 
1 nadir viewing scanner $\left( \pm 3^{\circ}\right)$, pointable to $\pm 8.5^{\circ}$, with a $90 \mathrm{~m}$ spatial resolution 2 and a $63 \mathrm{~km}$ swath. As a consequence of its high spatial resolution, the sensor has 3 a temporal repetitivity of 16 days. The MODIS sensor is an across track scanner $4\left( \pm 55^{\circ}\right)$ that collects, amongst other data, radiance measurements in 6 bands de5 signed for land surface temperature applications over the MIR (3-5 $\mu \mathrm{m})$ and TIR $6(8-12 \mu \mathrm{m})$ spectral ranges. The nadir spatial resolution is $1 \mathrm{~km}$, and the nomi7 nal swath is $2330 \mathrm{~km}$. As a consequence of its wide swath capability, the sensor 8 provides almost global coverage twice a day (ascending and descending orbits), 9 with a revisit in the same observation configuration every 16 days. Therefore, the 10 collected data sets provide directional samplings of the considered signals within this temporal window. Since they are carried by the same spacecraft, MODIS and 12 ASTER collect coincident nadir observations. Figure 1 displays the channel filter 13 response functions over the TIR domain for both sensors, and a typical example of atmospheric transmittance spectra calculated using the MODTRAN 4 radiative

transfer code along with the atmospheric profiles we considered in this study (see

$\S 2.3 .2$ ). The five ASTER TIR bands (numbered 10 to 14) are centered around 8.28, 8.63, 9.07, 10.65 and $11.28 \mu \mathrm{m}$. For MODIS, the three MIR bands (20, 22 and 23) are centered around $3.75,3.95$, and $4.05 \mu \mathrm{m}$, and the three TIR channels $(29,31$ and 32) are centered around 8.55, 11.03 and $12.02 \mu \mathrm{m}$. Figure 1 shows that MODIS band 29 matches ASTER band 11. MODIS band 31 overlaps both ASTER bands 13 and 14. Since spectral variations of emissivity are generally small around $11 \mu \mathrm{m}$, we could compare either bands 31 / 13 or bands $31 / 14$. Indeed, we observed that the two comparison schemes gave very similar results. From the channel fil- 
1 ter response functions and the atmospheric transmittance spectra calculated using

2 MODTRAN 4, we computed the waveband averaged atmospheric transmittance

3 over the ASTER and MODIS channels. A typical example (Table 1) shows that

4 MODIS channels 29 and 31 have slightly lower transmittances $(\sim 1-2 \%)$ than do

5 ASTER channels 11 and 13. The situation is reversed for the longer wavelengths,

6 where ASTER channel 14 has $\sim 1 \%$ lower transmittance than MODIS channel 31.

7 Since ASTER has no MIR band and MODIS has three TIR bands only, the MODIS

8 MIR channels 20,22, 23 and the ASTER TIR channels 10 and 12 were not consid-

9 ered when comparing brightness temperatures at the sensor and ground levels, and

10 surface emissivity retrievals.

[Fig. 1 about here.]

\subsection{The MODIS / TISIE and ASTER / TES algorithms}

14

Accurate estimation of surface emissivity and radiometric temperature from TIR remote sensing is a difficult task that requires separating their combined effects on the measured radiance. Indeed, separating surface emissivities and radiometric temperature is an under-determined problem since there is one more unknown than measurements. Consequently, over the past two decades much effort has been made to develop useful separation methods, as detailed by the reviews of Barducci and Pippi (1996); Caselles et al. (1997); Li et al. (1999); Sobrino et al. (2000) and Dash et al. (2002). There are essentially four types of separation methods: 1) split- 
1 window, 2) day-night pair, 3) temperature-independent spectral indices (TISIE),

2 and 4) TIR spectral contrast. The split-window method, focused on land surface

3 temperature, gave birth to many algorithms, some of them using auxiliary infor-

4 mation derived from either vegetation indices (Valor and Caselles, 1996; Sobrino

5 and Raissouni, 2000) or land surface type classification (Wan and Dozier, 1996;

6 Snyder et al., 1998). The day-night pair method proposed by Wan and Li (1997)

7 for the MODIS data relies on the iterative inversion of a simplified direct model-

8 ing of measurements. The system is then conditioned by the use of day-time and

9 night-time consecutive observations, inducing equal numbers of equations and un-

10 knowns. The TISIE method, originally developed by Becker and Li (1990) will

11 be detailed further when presenting the MODIS / TISIE algorithm (§ 2.2.1). The

12 last family of algorithms is based on the use of the spectral variation of emissiv-

13 ity over the TIR domain (Barducci and Pippi, 1996; Gillespie et al., 1998; Coll

14 et al., 2000), among which the TES method was designed by Gillespie et al. (1996,

15 1998) for the ASTER instrument. As explained in Introduction, TES and TISIE

16 were based on different assumptions which relied on the use of different types of

17 remote sensing information. The TES algorithm relied on an empirical relation

18 between the range of observed TIR emissivities and their minimum value. There-

19 fore, it required multispectral information over the TIR domain, but did not need

20 either multidirectional or multitemporal observations. The TISIE algorithm relied

${ }_{21}$ on MIR / TIR emissivity ratios raised to specific powers, along with a good es-

22 timation of the MIR emissivity by characterizing well the corresponding Bidirec-

23 tional Reflectance Distribution Function (BRDF). Therefore, it required remotely 
1 sensed data over the MIR and TIR spectral ranges, day time and night time consec-

2 utive observations, as well as multidirectional observations within a 16 day period

3 which corresponded the angular sampling of the required signals. The algorithms

4 we considered in this study were the TISIE version developed by Petitcolin and

5 Vermote (2002) for MODIS, and the TES version proposed by Schmugge et al.

6 (1998a, 2002a). Below are overviews of the algorithms. Detailed descriptions of

7 the MODIS / TISIE algorithms are given by Petitcolin et al. $(2002 a, b)$ and Petit-

8 colin and Vermote (2002). Detailed descriptions of the ASTER / TES algorithm

9 can be found in Gillespie et al. (1996, 1998) and Schmugge et al. (1998a, 2002a).

\section{$10 \quad$ 2.2.1 The MODIS / TISIE algorithm}

11 The basic idea of the TISIE approach, originally proposed by Becker and Li (1990), consists of calculating ratios of emissivities raised to specific power to character-

13 ize the emissivity relative variations without influence of surface temperature. This

14 is performed by both 1) using the Slater's approximation which expresses the sur-

${ }_{17} L_{g k}=\varepsilon_{k} L_{k} C_{k}$ where $\varepsilon_{k}$ is the channel emissivity, and $C_{k}$ a corrective factor

which accounts for the surface reflection of the atmospheric downwelling radiance

19 (Nerry et al., 1998). Then, the index $T I S I E_{j i}$ characterizes the emissivity relative

$20 \quad$ variation between two channels $i$ and $j$ :

$$
\operatorname{TISIE} E_{j i}=\frac{\varepsilon_{j}}{\varepsilon_{i}^{n_{j} / n_{i}}}=\varepsilon_{j}\left(\varepsilon_{i}\right)^{-n_{j i}}=\frac{a_{i}^{n_{j i}}}{a_{j}} \frac{L_{g j}}{C_{j}}\left[\frac{C_{i}}{L_{g i}}\right]^{n_{j i}}
$$


1 Li and Becker (1993) and Nerry et al. (1998) proposed next to use consecutive

2 night time and day time observations over the MIR and TIR channels $j$ and $i$, to

3 derive the magnitude of the MIR emissivity $\varepsilon_{j}$ from the corresponding bidirectional

4 reflectance $\rho_{j}$ by using the Kirchhoff's law $\varepsilon_{j}=1-\rho_{j}$. The MIR bidirectional

5 reflectance $\rho_{j}$ is retrieved from the day time MIR and TIR observations:

$$
\rho_{j}=\frac{1}{E_{j}^{s u n}}\left[L_{g j}^{d a y}-L_{e}\right]=\frac{1}{E_{j}^{s u n}}\left[L_{g j}^{d a y}-\operatorname{TISIE} E_{j i} \frac{a_{j}}{a_{i}^{n_{j i}}} \frac{C_{j}^{d a y}}{\left[C_{i}^{d a y}\right]^{n_{j i}}}\left[L_{g i}^{d a y}\right]^{n_{j i}}\right]
$$

7 where $E_{j}^{\text {sun }}$ is the incoming solar spectral radiance. The MIR emission component

$8 L_{e}$ is calculated using both the day time surface outgoing radiance $L_{g i}^{d a y}$ over the

9 TIR channel $i$, and day time $T I S I E_{j i}$. The latter is assumed to be equal to the night time $T I S I E_{j i}$, derived from the corresponding observations along with Equation 1.

11 When a multidirectional data set of MIR bidirectional reflectance $\rho_{j}$ can be derived 12 from multiangular MIR / TIR measurements along with Equation 2, it is possi- 
1 mental noise occurring over the MIR spectral range when characterizing the BRDF

2 from Equation 2, TISIE $E_{j i}$ are calculated as averaged values over the 16 day pe-

3 riod centered around acquisition dates of nadir observations. Finally, day time TIR

4 emissivity $\varepsilon_{i}$ is derived from MIR emissivity $\varepsilon_{j}$ using Equation 1, which allows

5 retrieving radiometric temperature. Considering averaged values of TISIE over a

616 day period and inverting a kernel-driven BRDF model over a multidirectional

7 data set collected during the same period relied on the assumption that changes in

8 land surface status within this temporal window do not impact dramatically either

9 TISIE or MIR BRDF. This was analyzed and discussed in details by Nerry et al.

10 (1998), Petitcolin et al. (2002a,b), and Petitcolin and Vermote (2002). We note that

11 the algorithm could use any of the three MODIS MIR and TIR channels since Petit-

12 colin and Vermote (2002) showed the consistency between the retrievals regardless

13 of chosen channels.

[Fig. 2 about here.]

15

\subsubsection{The ASTER / TES algorithm}

The TES algorithm combines interesting features of three previous approaches, with improvements to obtain a better accuracy on the estimates of emissivity absolute values. It is closely related to the Mean-MMD method proposed by Matsunaga (1994), and uses the Normalized Emissivity Method (NEM, (Gillespie, 1985)) to estimate surface radiometric temperature, from which emissivity ratios are derived using the Ratio algorithm (Watson, 1992). In order to reduce instrumental noise, the spectral shape of emissivity is derived using ratios of channel emissivities to 
1 their mean value $\bar{\varepsilon}$. The magnitude is estimated using a relationship between the

2 emissivity minimum value $\varepsilon_{\min }$ and the amplitude of emissivity spectral variations.

3 The latter is characterized using the Maximum Minimum Difference $(M M D)$, i.e.

4 the ratio of the difference between the emissivity maximum and minimum values

5 (i.e. $\varepsilon_{\max }$ and $\left.\varepsilon_{\min }\right)$ to the mean value $\bar{\varepsilon}$ :

$$
M M D=\frac{\varepsilon_{\max }-\varepsilon_{\min }}{\bar{\varepsilon}}
$$

6 Therefore, the algorithm relies on a semi-empirical power-law relationship between $7 \varepsilon_{\min }$ and $M M D$, such as $\varepsilon_{\min }$ decreases when $M M D$ increases (see Figure 1 in 8 Schmugge et al. (1998a)):

$$
\varepsilon_{\min }=A+B \times M M D^{C}
$$

9 This relationship requires a previous calibration of the $A, B, C$ coefficients over a 10 database of measured emissivity spectra. In this study, we used coefficients pro11 posed by Schmugge et al. (1998a) and calibrated over samples collected around the 12 world: $A=0.994, B=-0.687, C=0.737$. Calculation of MMD requires knowl13 edge of minimum, maximum and mean values of emissivity. The latter are deduced approach. 
1 The TES algorithm was theoretically and experimentally analyzed by Gillespie

2 et al. (1996), Gillespie et al. (1998), and Schmugge et al. (1998a). Next, it was

3 successfully applied by Schmugge et al. (2002a) on the HAPEX-Sahel / Thermal

4 Infrared Multispectral Scanner (TIMS) data set, and by Schmugge et al. (2002b)

5 on ASTER data collected over the Jornada Range located in northern Chihuahuan

6 desert, NM, USA. In the present study, the TES algorithm was applied to single

7 directional ASTER data collected at a given time. Therefore, the ASTER emissivi-

8 ties were instantaneous estimates, as compared to the MODIS emissivities derived

9 from measurements collected over 16 day periods.

\subsection{Data set: description and preprocessing}

\subsubsection{The Jornada and Central African Republic data sets}

12 The two areas selected for the comparison were located in the Central African Re13 public and in southern New Mexico, USA. The Africa scenes were collected over the St-Floris National Park (latitude 9.54N, longitude 21.53E). They were chosen 15 for the validation of a new fire detection algorithm (Petitcolin and Vermote, 2002) 16 since the scenes included many active fires. The area was typical of a Savannah 
1 from ground, airborne and satellite platforms (Havstad et al., 2000). The study

2 site, located in the northern Chihuahuan Desert, is typical of a semi-arid region

3 with sparse vegetation including grass, mesquite, tarbush and creosote bushes. The

4 ASTER scene represented a heterogeneous pattern since it included the San An-

5 dres mountain chain, semi-arid rangelands, the irrigated agricultural areas along

6 the Rio Grande, and the White Sands National Monument, an area of extensive

7 gypsum sand dunes. The ASTER / MODIS scenes, corresponding to coincident

8 nadir observations, were acquired on November 23, 2000 over Africa and May 12,

92001 over the Jornada, around 10:30 am at local solar time, i.e. 10:25 am Stan-

10 dard Time for Africa and 11:00 am Mountain Standard Time for the Jornada. The

11 preprocessed images were provided on-line by the United States Geological Sur-

12 vey / Distributed Active Archive Center / Earth Resources Observation System

13 (EROS) Data Center (USGS / DAAC / EDC), and consisted of radiometrically

14 and geometrically corrected radiances at the sensor level. The scene sizes approx-

15 imately corresponded to the sensor swath dimensions, i.e. squares of $63 \times 63$ and

${ }_{16} 2330 \times 2330 \mathrm{~km}^{2}$, for ASTER and MODIS, respectively. These images of bright-

17 ness temperature at the sensor level were provided with estimated accuracies about

$180.1 \mathrm{~K}$ for MODIS (Xiong et al., 2002) and $1 \mathrm{~K}$ for ASTER (Fujisada, 1998; Fujisada

19 et al., 1998). We observed brightness temperature values ranging between 295 and

20 $320 \mathrm{~K}$ for both the Africa and Jornada scenes, indicating that the observed targets

21 were hot surfaces. However, the mean value was higher for the Jornada (around

$22315 \mathrm{~K}$ ) than for Africa (around $305 \mathrm{~K}$ ). 


\section{2.3.2 Atmospheric corrections}

2 Both the TES and TISIE algorithms required band by band atmospheric correc-

3 tions, to obtain estimates of surface outgoing and atmospheric downwelling ra-

4 diances. These were performed using the radiative transfer model MODTRAN 4

5 along with atmospheric profiles generated by the National Center for Environmen-

6 tal Prediction (NCEP). As explained in Introduction, we used the same atmospheric

7 profiles for both sensors when characterizing atmosphere state for MODTRAN 4

8 calculations. The latter were then used to compute MODIS and ASTER waveband

9 integrated values of the atmospheric radiative properties: transmittance $\tau_{\text {atm }}$, up-

10 welling and downwelling radiance $L_{\text {atm }}^{\uparrow}$ and $L_{\text {atm }}^{\downarrow}$. Surface outgoing radiance $L_{\text {sur }}$

11 was next derived from at sensor radiance $L_{\text {sen }}$ using the radiative transfer equation:

$$
L_{s u r}=\frac{L_{s e n}-L_{a t m}^{\uparrow}}{\tau_{a t m}}
$$

The NCEP profiles were generated using a reanalysis procedure which incorporated the relevant measurements in an atmospheric model to produce a consistent representation of the atmosphere (Derber et al., 1991; Derber and Wu, 1998). They provided estimates of pressure, temperature and humidity from 1000 to $10 \mathrm{mb}$, and were available on a grid having a spatial resolution of $1^{\circ}$ in latitude / longitude.

The choice of atmospheric correction strategies was driven by the swath dimensions of the sensors. Since that of ASTER was about $63 \mathrm{~km}$, i.e. around $0.5^{\circ}$ in latitude / longitude, the closest NCEP profile was used, and we therefore assumed that the atmospheric radiative properties were uniform within the scene. For the MODIS data, 
1 however, the $2330 \mathrm{~km}$ swath dimension required accounting for the spatial variabil-

2 ity of these radiative properties within the scene. For this, we used a spatial interpo-

3 lation procedure. The MODTRAN 4 calculations were performed for each profile

4 of the NCEP grid included within the MODIS scene. Then, the atmospheric radia-

5 tive variables computed from MODTRAN 4 calculations (i.e. transmittance, up-

6 welling and downwelling radiances), were bi-linearly interpolated to each MODIS

7 pixel. The validity of this spatial interpolation procedure was previously verified by

8 Petitcolin and Vermote (2002). The NCEP profiles, that started at $1000 \mathrm{mb}$ pres-

9 sure level, were truncated according to the ground altitude at the profile locations.

10 Moreover, ground based meteorological measurements were routinely collected at

11 the Jornada Range. Therefore, in addition to the NCEP profile used to process the

12 ASTER data collected over the Jornada, we also considered an adjusted profile in-

13 corporating surface temperature and humidity conditions recorded on site. By using

14 such an adjusted profile, it was assumed to provide more realistic information when

15 characterizing the atmosphere, as compared to the NCEP profile, although the spa-

16 tial variation of surface temperature and humidity conditions could be significant

17 within the $63 \times 63 \mathrm{~km}^{2}$ size ASTER scene. This adjusted profile was not considered

18 when performing atmospheric corrections on MODIS data since the procedure we

19 used for this sensor was based on a spatial interpolation. We note that the atmo-

20 spheric corrections of the MODIS data were performed for the day time and night

21 time observations collected within the 16 day temporal window.

22 As mentioned previously ( $\S 2.3 .1$ ), we noted large values of brightness tempera-

23 ture at the sensor level, which corresponded to large values of surface temperature. 
1 According to the observations reported by Jacob et al. (2003), the dominant at-

2 mospheric effect when observing hot surfaces is absorption by atmospheric water

3 vapor. The latter drives the atmospheric transmittance (Becker, 1987) such as an

4 increase of water vapor induces a decrease of atmospheric transmittance. Conse-

5 quently, using a wetter atmospheric profile induces larger surface brightness tem-

6 peratures after atmospheric corrections (see Equation 5). Since we used different

7 atmospheric correction strategies according to the sensor swaths, we first compared

8 the atmospheric Water Vapor Content (WVC) of the four profiles surrounding the

9 ASTER scene (see Table 2). Both the magnitude and the variability of these WVC

10 values were lower for Africa as compared to the Jornada. For Africa, the profile

11 closest to the ASTER scene had a WVC slightly lower than the mean value over

12 the four surrounding profiles. For the Jornada, we observed the same trend, but the

13 difference was larger. The adjusted profile used to process the ASTER scene col-

14 lected over the Jornada had an intermediate WVC value between that of the closest

15 profile and the mean value over the four surrounding profiles. These observations

16 will be further used to explain the differences between the ASTER and MODIS

17 brightness temperatures at the sensor and ground levels.

[Table 2 about here.]

\subsubsection{Superposition of the MODIS and ASTER images}

The last step of the preprocessing dealt with the superposition of the MODIS and

ASTER coincident nadir images, which consisted of aggregating the ASTER pix-

els matching the footprint of each MODIS pixel. The georegistration information 
1 was provided together with the radiance data. Those we considered to perform the 2 superposition were 1) the geographic location of the center of each MODIS pixel, 3 2) the geographic coordinates of the center of the ASTER scene and 3) the rotation 4 angle between the ASTER radiance images and the Universal Transverse Mercator 5 (UTM) projection to be used. Since both instruments were on the same platform, 6 the accuracy of the image superposition was expected to be very good, although it 7 could not be assessed. As a consequence of the triangular line spread function of the MODIS sensor (Barnes et al., 1998), the MODIS pixel footprint was about $1 \mathrm{~km}$ 9 along track and $2 \mathrm{~km}$ across track. Therefore, we applied to each ASTER pixel a 12 pixel.

triangular - symmetric weighting function that accounted for the across track distance between the considered pixel and the center of the corresponding MODIS

In order to assess the impact of surface heterogeneities within MODIS pixels, we performed the comparisons of MODIS and ASTER surface radiometric temperature retrievals by considering different levels of variability of the $11 \times 11$ aggregated ASTER values $(90 \mathrm{~m})$ inside the corresponding MODIS pixel $(1 \mathrm{~km})$. If the standard deviation of the radiometric temperature was larger than a given threshold value, the MODIS and ASTER pixels were not considered. The threshold values we choose were $2.5,1$, and $0.5 \mathrm{~K}$, respectively. In the following, we first present the comparison results we obtained when considering the $2.5 \mathrm{~K}$ threshold value. We note that we obtained very similar comparison results when considering either the whole data set without any filter or the data set filtered with the $2.5 \mathrm{~K}$ threshold value. Finally, we consider the results for the three threshold values, to assess the 
1 mixed effects of surface heterogeneities and sensor spatial resolutions.

\section{Results and discussion}

\subsection{Comparing brightness temperature at the sensor level}

4 Figure 3 and Table 3 display the comparison of the Top Of Atmosphere (TOA)

5 or at sensor level estimates of Brightness Temperature (BT), for the three sets of

6 ASTER / MODIS intercompared channels, when considering the coincident nadir

7 observations from both sensors. The agreements were very good for Africa, with

$8 \mathrm{RMSD}^{1}$ values ranging between 0.28 and $0.42 \mathrm{~K}$. The discrepancy was also low for

9 the Jornada, although larger, with RMSD values ranging between 0.36 and $1.22 \mathrm{~K}$.

10 The better agreement we observed for Africa was ascribed to both 1) lower atmo-

11 spheric Water Vapor Content (WVC) magnitude and variability (see third paragraph

12 of $\S 2.3 .2$ ), and 2) lower surface brightness temperatures (see end of $\S 2.3 .1$ ). Indeed, atmospheric absorption effects increase with both surface temperature and 14 atmospheric WVC when observing hot surfaces (Jacob et al., 2003). The MODIS

15 values were systematically and slightly lower when comparing either bands 29/11 or $31 / 13$, and systematically larger when comparing bands $31 / 14$, with bias ${ }^{2}$ 17 values ranging from -0.38 to $1.19 \mathrm{~K}$. This was consistent with the observations reported when comparing the waveband averaged atmospheric transmittances over

MODIS and ASTER channels (see end of $\S 2.1$ ). However, there was no obvi-

1 The RMSD (Root Mean Square Difference) is the mean quadratic difference between two predicted variables.

2 The bias is the averaged difference between two different estimates. 
1 ous correlation between the magnitudes of these bias values (Table 3) and the

2 differences between the MODIS / ASTER waveband averaged atmospheric trans-

3 mittances (Table 1). This might be explained by coupling effects between surface

4 emissivity variations, atmospheric perturbations and channel filter response func-

5 tions. Indeed, the difference between the TOA BT estimates did not depend on

6 atmospheric transmittance only, but also on surface emitted / reflected radiance,

7 which was driven by surface emissivity. Therefore, the spectral variations of both

8 surface emissivity and atmospheric effects induced different waveband brightness

9 temperatures at the sensor level, since the filter response functions of the intercom-

10 pared MODIS / ASTER channels did not match exactly. The standard deviation

11 of the ASTER aggregated values inside MODIS pixels ranged between 0.99 and

$121.24 \mathrm{~K}$ (see Table 3). These values resulted from the atmosphere smoothing effect

13 on the spatial variability of the surface outgoing radiance. Finally, the large RMSD

14 value between ASTER band 14 and MODIS band 31 TOA BT for the Jornada was

15 very close to the bias value, whereas the low biases observed in the other cases

16 corresponded to RMSD values ranging between 0.3 and $0.5 \mathrm{~K}$. Therefore, the ran-

17 dom differences were lower than $0.5 \mathrm{~K}$, and the systematic differences might be

18 explained by combined effects of surface emissivity variations, atmospheric pertur-

19 bations, and channel filter response functions. Besides, these differences were close

20 to the estimated accuracies previously mentioned when presenting the MODIS and

$21 \quad$ ASTER products of brightness temperature at the sensor level $(\S 2.3 .1)$. This led us

22 to conclude that measurements from both instruments agreed well, which increased

23 the confidence one could have in the instrumental preprocessing, both radiometric 
1 and geometric.

\section{$4 \quad 3.2$ Comparing brightness temperature at the surface level}

${ }_{5}$ Figure 4 displays the scatterplots of MODIS and ASTER estimates of brightness

6 temperature at the surface level, called here Surface Brightness Temperature (SBT),

7 after the atmospheric corrections of the coincident nadir observations. These scat-

8 terplots were obtained by considering the MODIS and ASTER data atmospheri-

9 cally processed using the NCEP profiles truncated according to the ground altitude

10 at the profile locations. The first two rows of Table 4 display the statistical results

11 of these scatterplots. Regardless of considered scene and intercompared bands, the

12 MODIS SBT estimates were systematically larger than the ASTER ones. Never-

13 theless, the differences between MODIS and ASTER retrievals were very low for

14 Africa (RMSD between 0.42 and $0.46 \mathrm{~K}$, bias between 0.18 and $0.32 \mathrm{~K}$ ), and larger

15 for the Jornada (RMSD between 1.01 and $1.43 \mathrm{~K}$, bias between 0.89 and $1.35 \mathrm{~K}$ ).

${ }_{16}$ The better comparison results we observed for Africa could be explained by the

17 observations reported in the third paragraph of $\S$ 2.3.2. First, we noted for Africa,

18 as compared to the Jornada, a lower difference between the atmospheric WVC

19 value of the NCEP profile used to process the ASTER data and the WVC aver-

20 aged value over the four surrounding profiles used to process the MODIS data.

${ }_{21}$ Second, we noted a lower variability of the WVC values of the four surrounding 
1 profiles, which induced a larger similitude between the two different atmospheric

2 correction strategies we chose according to the sensor swaths (see second para-

3 graph of $\S 2.3 .2$ ). The systematically larger values observed with MODIS for both

4 Africa and the Jornada were assumed to result from larger atmospheric correc-

5 tions applied to the MODIS data. Indeed, the WVC averaged values over the four

6 surrounding NCEP profiles used to process the MODIS images were larger than

7 the WVC values of the single NCEP profiles used to process the ASTER images

8 (see third paragraph of $\S 2.3 .2$ ). This induced larger MODIS SBT values since the

9 waveband averaged atmospheric transmittances were lower (see Equation 5). This

10 assumption was confirmed by performing atmospheric corrections of ASTER data

11 collected over the Jornada with the adjusted NCEP profile, which corresponded to

12 a WVC increase about $0.11 \mathrm{~g} . \mathrm{cm}^{-2}$ as compared to the profile truncated according

13 to the ground altitude at the profile location (see Table 2). The third row of Table 4,

14 labeled "Jornada Adjusted NCEP for ASTER" displays the comparison results for

15 the Jornada when considering the adjusted NCEP profile to atmospherically correct

16 the ASTER data, and the NCEP profiles truncated according to the ground altitude

17 at the profile locations to process the MODIS data. In this case, we observed an

18 increase of the ASTER SBT by $0.2 \mathrm{~K}$ regardless of channel (third row of Table 4

19 as compared to the second). Nevertheless, the MODIS values still were systemati-

20 cally larger as compared to those derived from ASTER. Therefore, we decided to

${ }_{21}$ atmospherically correct the ASTER / Jornada data by using a profile having the

22 same WVC as the averaged value over those used to process the MODIS / Jor-

23 nada data (see Table 2). For this, we increased the humidity of the adjusted NCEP 
1 profile by $5 \%$ in relative terms. The results are displayed in Table 4 with the label

2 "Jornada Shifted NCEP for ASTER". It is shown that the resulting increase of the

3 ASTER SBT was not the same from one channel to another (fourth row of Table 4

4 as compared to the third). The remaining differences could result from the spatial

5 variability of the atmospheric variables (atmospheric transmittance, upwelling and

6 downwelling radiances) bi-linearly extrapolated from the four surrounding profiles

7 and next used to process MODIS data, as compared to the atmosphere uniformity

8 we assumed when processing the ASTER data. Although the validity of the spa-

9 tial interpolation method we used was previously shown (Petitcolin and Vermote,

10 2002), the remaining differences might also result from this bi-linear interpolation,

11 as mentioned by Schroedter et al. (2003) who proposed a most robust approach

12 based on the Shepard's method. However, we suspected at this stage that the main

13 reason of these remaining differences for the Jornada was the combined effects of

14 the surface emissivity variations and the filter response functions of the intercom-

15 pared MODIS / ASTER channels which did not match exactly. Indeed, the Jornada

16 scene included gypsum sand dunes and bare soils of both agricultural and semi-arid

17 areas, which had large spectral variations of emissivity (Schmugge et al., 2002a,b).

18 In contrast, the Africa scene included mainly vegetative areas which generally have

19 low spectral variations of emissivity. Finally, the spatial variability of ASTER SBT

20 within MODIS pixels was about $1.3 \mathrm{~K}$. These larger values, compared to the stan-

${ }_{21}$ dard deviation of the aggregated values of ASTER TOA BT, were explained by

22 the removal of the atmosphere smoothing effect after atmospheric corrections. We

23 noted that the standard deviation values at 8.5 and $11 \mu \mathrm{m}$ were similar for Africa, 
1 and quite different for the Jornada. This was explained by the spatial variability

2 of emissivity at $8.5 \mu \mathrm{m}$ inside the ASTER Jornada scene, and was consistent with

3 the results reported by Schmugge et al. (2002b). For further investigations with the

4 Jornada data, we selected the ASTER SBT estimates which were the closest to the

5 MODIS ones, i.e. those computed using the shifted NCEP profile.

$8 \quad 3.3$ Comparing surface emissivity and radiometric temperature
[Fig. 4 about here.]

[Table 4 about here.]

9 Figure 5 and Table 5 display the comparison of MODIS and ASTER emissivity estimates. MODIS retrievals were obtained by applying the calculated TIR emis11 sivities to the surface brightness temperature images, where the TIR emissivities 12 were derived both characterizing the MIR BRDF and computing TISIE over a 16 day period. ASTER retrievals were derived from the five surface brightness temperature images. Consequently, the time meanings of ASTER and MODIS estimates were significantly different. This induced difficulties to link the comparison results for emissivity or radiometric temperature to those obtained when dealing with SBT. For Africa, the ranges of emissivity estimates from both sensors were quite narrow, i.e. between 0.93 and 0.97 , regardless of intercompared channels. 
1 bias values ranging from 0.006 to 0.009 , and from -0.0004 to 0.005 , respectively).

2 For the Jornada, the ranges of emissivity estimates from both sensors at $8.6 \mu \mathrm{m}$

3 were broader as compared to those observed for Africa, i.e. between 0.84 and 0.96 .

4 These larger ranges were explained by the extensive gypsum sand dunes and the

5 Jornada semi-arid rangeland, which both had low values of emissivity at $8.6 \mu \mathrm{m}$

6 (Schmugge et al., 2002b). In contrast, the ranges at $11 \mu \mathrm{m}$ were similar to those

observed for Africa. This was explained by the emissivity variations for natural

8 surfaces which are generally low around this wavelength. The comparison results

9 were not as good as those observed for Africa, but they were acceptable (RMSD

10 and bias values ranging from 0.008 to 0.016 , and from -0.01 to 0.002 , respectively).

11 For both study areas, the ranges of MODIS and ASTER values at $8.6 \mu \mathrm{m}$ were very

12 similar, whereas the range of MODIS emissivity at $11 \mu \mathrm{m}$ was larger as compared

13 to that of ASTER estimates (see Figure 5). For the latter wavelength, the scatter-

14 plots indicated low correlations between MODIS and ASTER retrievals. We might

15 in this case have reached the limitations of both algorithms. At the high end, the

16 lower ASTER values could be due to the gray body problem of TES, when MMD

17 values become very low. As a result ASTER did not observe the higher emissivities

18 for vegetated fields. For the low end, the MODIS results were not consistent with

19 the laboratory emissivity spectra derived from samples collected over the Jornada.

20 Indeed, these spectra did not yield many values around and below 0.95 at $11 \mu \mathrm{m}$

${ }_{21}$ (Schmugge et al., 2002b). However, the lower MODIS values could result from

22 the large scale of the MODIS data, as noted by Becker and Li (1995) when dealing

23 with coarser spatial resolutions. The values of the standard deviation of the ASTER 
1 emissivities inside MODIS pixels varied significantly from one channel to another

2 for both study areas, and were systematically larger at $8.6 \mu \mathrm{m}$. This was explained

3 by the emissivity variability which is generally larger at this wavelength than at $411 \mu \mathrm{m}$.

[Fig. 5 about here.]

7 Figure 6 and Table 6 display the comparison of the MODIS and ASTER retrieved 8 Surface Radiometric Temperatures (SRT). For Africa, the estimates were very close, 9 with a low RMSD value and a negligible bias value ( 0.5 and $0.06 \mathrm{~K}$ respectively). Besides, the RMSD value was very close to those observed for SBT. For the Jor11 nada, the MODIS values were larger than those from ASTER. The discrepancy was 12 ascribed to the differences between the intrinsic features of the algorithms regarding surface properties, whereas no explanation was found for the remaining bias. Overall, the RMSD values, i.e. $0.5 \mathrm{~K}$ for Africa and $0.86 \mathrm{~K}$ for the Jornada, were lower 
1 sand dune, agricultural fields and semi-arid rangelands). At the lower scale, i.e.

2 kilometer scale, however, the Jornada scenes displayed a lower spatial variability

3 since a given type of land use was more homogeneous than Savannah bushes.

6 The differences between ASTER and MODIS emissivities / SRT could be ex7 plained by the assumptions the algorithms relied on, and their resulting limitations.

8 Petitcolin and Vermote (2002) observed a low signal to noise ratio when fitting the

9 Li-Ross BRDF kernel driven model over the MODIS retrieved MIR reflectances, 10 which could induce significant errors when estimating the MIR and then the TIR 11 emissivities. Moreover, the multidirectional MIR reflectance data sets provided di12 rectional samplings in a plane that is $\sim 35^{\circ}$ from the principal plane, whereas Weiss et al. (2002) showed that the performances of BRDF kernel-driven models can be poor outside the principal plan. Besides, the algorithm assumes that both TISIE and MIR BRDF do not change dramatically over 16 day periods. As explained 16 in $\S 2.2 .2$, the TES algorithm relies on a semi-empirical relationship between the minimum value and the contrast of emissivity, which was previously calibrated using emissivity spectra measured in laboratory from samples collected around the world (Schmugge et al., 1998a). However, there were probably significant differences between the laboratory measurements and the larger scale of the ASTER data. Indeed, the laboratory samples used for the calibration of the TES empirical relationship were homogeneous whereas the algorithm was applied on ASTER 
$190 \mathrm{~m}$ spatial resolution pixels which depicted spatial heterogeneities. Nevertheless,

2 we were more confident in the ASTER retrievals for the Jornada, since they agreed

3 well with ground based measurements, especially over the relatively homogeneous

4 White Sands gypsum dunes (Schmugge et al., 2002b). A better understanding of the

5 good comparison results for radiometric temperature despite differences in emis-

6 sivity retrievals at $11 \mu \mathrm{m}$ would require deeper investigations on both algorithms,

7 which was out of the scope of this study. We note that we observed significant dif-

8 ferences (up to $2 \mathrm{~K}$ ) between algorithm SRT retrievals when considering ASTER

9 SBT computed using the raw NCEP profile rather than the shifted one. This em-

10 phasized the strong influence of the atmospheric performances on those of the TES

11 algorithm, as previously observed by Schmugge et al. (1998a).

123.4 Assessing the combined effects of surface heterogeneity and spatial resolution

13 Finally, we assessed the combined effects of spatial resolution and heterogeneity

14 by comparing the MODIS and ASTER radiometric temperature estimates for dif-

15 ferent levels of variability of the ASTER radiometric temperature retrievals. As

16 previously explained (end of $\S 2.3 .3$ ), the level of variability was characterized

17 using threshold values of the standard deviation of the ASTER radiometric temper-

18 atures aggregated inside MODIS pixels. The comparison of the algorithm retrievals

19 for the different threshold values are displayed in Table 7. The lower the threshold

value, the better were the comparison results. This indicated that both algorithms

agreed better when the spatial variability was lower. However, the difference be-

tween the maximum and minimum RMSD values of radiometric temperature when 
1 considering the three threshold values was $0.16 \mathrm{~K}$ and $0.26 \mathrm{~K}$ for Africa and the

2 Jornada, respectively. This showed that the spatial variability was not a critical is-

3 sue for the scenes we considered. It was consistent with the comparison results we

4 obtained when running the TES algorithm over the ASTER scenes degraded to the

5 MODIS spatial resolution, since we did not observed significantly different results.

6 These observations led us to conclude that the MODIS / TISIE and ASTER / TES

7 algorithms were robust regarding the spatial variability within these study areas.

[Table 7 about here.]

\section{Conclusion}

The scope of this study was to compare estimates of surface emissivity and radiometric temperature derived from measurements collected using the MODIS and ASTER sensors. Two areas were selected to conduct the comparison. The first area, called the Jornada, was located in northern Chihuahuan desert, NM, USA; and included semi-arid rangelands, agricultural areas, mountainous areas and gypsum sand dunes. The second area was a Savannah landscape located in the Central African Republic, central Africa. The MODIS and ASTER estimates were retrieved using the TISIE algorithm proposed by Petitcolin and Vermote (2002), and the TES algorithm proposed by Schmugge et al. (1998a, 2002a), respectively. Such investigations were of interest since the algorithms relied on different assumptions according to the temporal, spectral and directional information provided by each sensor. The comparison between MODIS / TISIE and ASTER / TES retrievals 
1 was possible since ASTER and MODIS are on board the same platform, which

2 eliminated temporal problems due to the non stable nature of kinetic temperature.

3 For a better understanding of the results we obtained when comparing surface ra-

4 diometric temperatures and emissivities, we first intercompared the intermediate

5 variables, i.e. brightness temperatures at the sensor and surface levels. Intercom-

6 parisons of brightness temperatures and emissivities were performed for ASTER /

7 MODIS matching bands at 8.6 and $11 \mu \mathrm{m}$.

8 Both TES and TISIE algorithms required performing atmospheric corrections to 9 estimate surface outgoing and atmospheric downwelling radiances. These correc10 tions were performed using the MODTRAN 4 radiative transfer code along with 11 NCEP profiles. We used the same profiles for both sensors when characterizing at12 mosphere state. However, the instrument swaths led us to use different strategies 13 when considering the spatial variability of the atmosphere radiative properties. The 
1 state may not be sufficient to perform accurate atmospheric corrections. Indeed,

2 these require accounting for the atmospheric spatial variability when the level of

3 the latter is large.

4 When comparing emissivity estimates, we observed very good agreements for Africa.

5 The agreement for the Jornada was also good despite larger discrepancies as com-

6 pared to Africa. Overall, the differences ranged between 0.006 and 0.016 . The

7 broad range of emissivity at $8.6 \mu \mathrm{m}$ for the Jornada was well displayed by both

8 sensors. However, we observed a larger range of MODIS emissivity values com-

9 pared to that of ASTER retrievals at $11 \mu \mathrm{m}$ for both study areas. The larger MODIS

10 values were ascribed to the gray body problem of the TES algorithm, whereas the

11 lower MODIS values were not consistent with the emissivity laboratory spectra

12 derived from samples collected over the Jornada. When comparing surface radio-

13 metric temperature estimates, once more, the results were excellent for Africa and

14 good for the Jornada. Overall, the remaining differences $(0.9 \mathrm{~K})$ were lower than

15 the TES / TISIE accuracies reported by previous studies, and corresponded to the

16 requirement for many applications. Since the applied atmospheric corrections were

17 performed such as surface brightness temperature estimates from both sensors were

very close, these remaining differences could results from the experimental context,

the differences in time meaning of ASTER and MODIS retrievals, and the differ-

ent underlaying physics of both algorithms. Finally, we assessed a possible impact

of the combination of the sensor spatial resolutions and the spatial variability dis-

played by the observed natural surfaces. It was shown that these combined effects

were not critical for the study areas we considered. 
1 The low differences in surface radiometric temperature we observed indicated the

2 agreement between the algorithms and their consistencies. However, it was not

3 possible to draw a general conclusion that would require a larger database and

4 therefore much attention on the performances of the atmospheric corrections at

5 the global scale. It was shown that the combined effects of sensor spatial reso-

6 lution and spatial variability were not critical for the study areas we considered.

7 Therefore, ASTER and MODIS TIR products should be used in the framework of

8 the JORNEX campaign for future investigations focused on spatial and temporal

9 issues in remote sensing. First, aggregation processes that occur when modeling

10 surface energy fluxes at the MODIS scale may be studied using ASTER high spa-

11 tial resolution data. Second, the complementarity between both sensor revisits, i.e.

1216 days for ASTER and everyday for MODIS, will be of interest to assess strate-

13 gies of data assimilation in modeling approaches which dynamically describe en-

14 ergetic exchanges at the surface - atmosphere interface (Olioso et al., 1999, 2002).

15 Finally, extending ASTER results over a limited area to the global scale provided

16 by MODIS is a promising issue (Zhou et al., 2003). Merging ASTER and MODIS

17 emissivity data may further results in worldwide emissivity maps which take ad-

18 vantage of both sensors in terms of spatial and temporal sampling and coverage.

\section{Acknowledgments}

This study was supported by the ASTER and MODIS Projects of NASA's EOSTERRA Program. The authors wish to thank reviewers for valuable comments. 


\section{References}

Barducci, A., Pippi, Y., 1996. Temperature and emissivity retrieval from remotely sensed images using the "Grey Body Emissivity" method. IEEE Transactions on Geoscience and Remote Sensing 34, 681-695.

Barnes, W., Pagano, T., Salomonson, V., 1998. Prelaunch characteristics of the Moderate Resolution Imaging Spectroradiometer (MODIS) on EOS-AM1. IEEE Transactions on Geoscience and Remote Sensing 36, 1088-1100.

Becker, F., 1987. The impact of spectral emissivity on the measurement of land surface temperature from a satellite. International Journal of Remote Sensing 8, $1509-1522$.

Becker, F., Li, Z., 1990. Temperature Independent Spectral Indices in thermal infrared bands. Remote Sensing of Environment 32, 17-33.

Becker, F., Li, Z., 1995. Surface temperature and emissivity at various scale: definition, measurement and related problem. Remote Sensing Reviews 12, 225-253.

Berk, A., Bernstein, L., Anderson, G., Acharya, P., Robertson, D., Chetwynd, J., Adler-Golden, S., 1998. MODTRAN cloud and multiple scattering upgrades with application to AVIRIS. Remote Sensing of Environment 65, 367-375.

Caselles, V., Valor, E., Coll, C., Rubio, E., 1997. Thermal band selection for the PRISM instrument. Part 1. Analysis of emissivity-temperature separation algorithms. Journal of Geophysical Research 102, 11145-11164.

Coll, C., Caselles, V., Rubio, E., Sospedra, F., Valor, E., 2000. Temperature and emissivity separation from calibrated data of the Digital Airborne Imaging Spectrometer. Remote Sensing of Environment 76, 250-259.

Dash, P., Göttsche, F.-M., Olesen, F.-S., Fischer, H., 2002. Land surface temperature and emissivity estimation from passive sensor data: theory and practicecurrent trends. International Journal of Remote Sensing 23(13), 2563 - 2594.

Derber, J., Parrish, D., Lord, S., 1991. The new global operational analysis system at the National Meteorological Center (NMC). Weather and Forecasting 6, 538547.

Derber, J., Wu, W., 1998. The use of TOVS cloud-cleared radiances in the NCEP SSI analysis system. Monthly Weather Review 126, 2287-2299.

Fujisada, H., 1998. ASTER Level-1 data processing algorithm. IEEE Transactions on Geoscience and Remote Sensing 36, 1101-1112.

Fujisada, H., Sakuma, F., Ono, A., Kudoh, M., 1998. Designed and preflight performances of ASTER Instrument protoflight model. IEEE Transactions on Geoscience and Remote Sensing 36, 1152-1160.

Gillespie, A., 1985. Lithologic mapping of silicate rocks using TIMS. In: The TIMS data user workshop, June 18-19, 1985, JPL Publication, 86-38. pp. 29-44.

Gillespie, A., Rokugawa, S., Hook, S., Matsunaga, T., Kahle, A., 1996. Temperature / emissivity separation algorithm. Theoretical basis document, version 2.1, NASA/GSFC, Greenbelt, MD, USA.

Gillespie, A., Rokugawa, S., Matsunaga, T., Cothern, S., Hook, S., Kahle, A., 1998. A temperature and emissivity separation algorithm for Advanced Spaceborne Thermal Emission and Reflection radiometer (ASTER) images. IEEE Transac- 
tions on Geoscience and Remote Sensing 36, 1113-126.

Havstad, K., Kustas, W., Rango, A., Ritchie, J., Schmugge, T., 2000. jornada Experimental Range: a unique arid land location for experiments to validate satellite system. Remote sensing of Environment 53, 13-25.

Jacob, F., Gu, X., Hanocq, J.-F., Baret, F., 2003. Atmospheric corrections of single broadband channel and multidirectional airborne thermal infrared data. Application to the ReSeDA Experiment. International Journal of Remote Sensing 24, 3269-3290.

Jacob, F., Olioso, A., Gu, X., Su, Z., Seguin, B., 2002. Mapping surface fluxes using visible, near infrared, thermal infrared remote sensing data with a spatialized surface energy balance model. Agronomie: Agriculture and Environment 22, 669-680.

Justice, C., Vermote, E., Townshend, J., Defries, R., Roy, D., Hall, D., Salomonson, V., Privette, J., Riggs, G., Strahler, A., Lucht, W., Myneni, R., Knyazikhin, Y., Running, S., Nemani, R., Wan, Z., Huete, A., van Leeuwen, W., Wolfe, R., Giglio, L., Muller, J.-P., Lewis, P., Barnsley, M., 1998. The MODerate Imaging Spectroradiometer (MODIS) : land remote sensing for global change research. IEEE Transactions on Geoscience and Remote Sensing 36, 1228-1249.

Li, Z.-L., Becker, F., 1993. Feasibility of land surface temperature and emissivity determination from AVHRR data. Remote Sensing of Environment 43, 67-85.

Li,Z.-L., Becker, F., Stoll, M., Wan,Z., 1999. Evaluation of six methods for extracting relative emissivity spectra from thermal infrared images. Remote Sensing of Environment 69, 197-214.

Matsunaga, T., 1994. A Temperature-Emissivity Separation Method Using an Empirical Relationship between the Mean, the Maximum and the Minimum of the Thermal Infrared Emissivity Spectrum. Journal Remote Sensing Society of Japan 14, 230-241.

Nerry, F., Peticolin, F., Stoll, M., 1998. Bidirectional reflectivity in AVHRR Channel 3: Application to a region in Northern Africa. Remote Sensing of Environment 66, 298-316.

Norman, J., Becker, F., 1995. Terminology in thermal infrared remote sensing of natural surfaces. Remote Sensing Reviews 12, 159-173.

Ogawa, K., Schmugge, T., Jacob, F., French, A., 2002. Estimation of broadband land surface emissivity from multispectral thermal infrared remote sensing. Agronomie: Agriculture and Environment 22, 695-696.

Ogawa, K., Schmugge, T., Jacob, F., French, A., 2003. Estimation of land surface window $(8-12 \mu \mathrm{m})$ emissivity from multi-spectral thermal infrared remote sensing - A case study in a part of Sahara Desert. Geophysical Research Letter 30, 1067-1071.

Olioso, A., Braud, I., Chanzy, A., Courault, D., Demarty, J., Kergoat, L., Lewan, L., Ottlé, C., Prévot, L., Zhao, W., Calvet, J., Cayrol, P., Jongschaap, R., Moulin, S., Noilhan, J., Wigneron, J.-P., 2002. SVAT modeling over the Alpilles-ReSeDA experiment: comparison of SVAT models, first results on wheat. Agronomie: Agriculture and Environment Submitted.

Olioso, A., Chauki, H., Courault, D., Wigneron, J., 1999. Estimation of evapotran- 
spiration and photo-synthesis by assimilation of remote sensing data into SVAT models. Remote Sensing of Environment 68, 341-356.

Petitcolin, F., Nerry, F., Stoll, M.-P., 2002a. Mapping directional emissivity at 3.7 $\mu \mathrm{m}$ using a simple model of bi-directional reflectivity. International Journal of Remote Sensing 23, 3443-3472.

Petitcolin, F., Nerry, F., Stoll, M.-P., 2002b. Mapping temperature independent spectral indice of emissivity and directional emissivity in avhrr channels 4 and 5. International Journal of Remote Sensing 23, 3473-3491.

Petitcolin, F., Vermote, E., 2002. Land surface reflectance, emissivity and temperature from MODIS middle and thermal infrared data. Remote Sensing of Environnement 83, 112-134.

Schmugge, T., French, A., Ritchie, J., Rango, A., Pelgrum, H., 2002a. Temperature and emissivity separation from multispectral thermal infrared observations. Remote Sensing of Environment 79, 189-198.

Schmugge, T., Hook, S., Coll, C., 1998a. Recovering Surface Temperature and Emissivity from Thermal Infrared Multispectral Data. Remote Sensing of Environment $65,121-131$.

Schmugge, T., Jacob, F., French, A., Ritchie, J., Chopping, M., Rango, A., 2002b. ASTER thermal infrared observations over New Mexico. In: IGARSS'2002 (Totonto, Canada), International Geoscience and Remote Sensing Symposium (Piscataway, NJ: IEEE). p. In press.

Schmugge, T., Kustas, W., 1999. Radiometry at infrared wavelengths for agricultural applications. Agronomie: Agriculture And Environment 19, 83-96.

Schmugge, T., Kustas, W., Humes, K., 1998b. Monitoring Land Surface Fluxes Using ASTER Observations. IEEE Transactions on Geoscience and Remote Sensing 36, 1421-1430.

Schroedter, M., Olesen, F.-S., Fischer, H., 2003. Determination of land surface temperature distributions from single channel IR measurements: an effective spatial interpolation method for the use of TOVS, ECMWF, and radiosonde profiles in the atmospheric correction scheme. International Journal of Remote Sensing 24, 1189-1196.

Seguin, B., Becker, F., Phulpin, T., Gu, X., Guyot, G., Kerr, Y., King, C., Lagouarde, J., Ottlé, C., Stoll, M., Tabbagh, T., Vidal, A., 1999. IRSUTE: A minisatellite project for land surface heat flux estimation from field to regional scale. Remote Sensing of Environment 68, 357-369.

Snyder, W., Wan, Z., Zhang, Y., Feng, Y.-Z., 1998. Classification-based emissivity for land surface temperature measurement from space. International Journal of Remote Sensing 19, 2753-2774.

Sobrino, J., Raissouni, N., 2000. Toward remote sensing methods for land cover dynamic monitoring. Application to Morroco. International Journal of Remote Sensing 21, 353-366.

Sobrino, J., Raissouni, N., Li, Z., 2000. A comparative study of land surface emissivity retrieval from NOAA data. Remote Sensing of Environment 75, 256-266.

Valor, E., Caselles, V., 1996. Mapping land surface emissivity from NDVI : application to European, African and South American areas. Remote Sensing of 
Environment 57, 167-184.

Wan, Z., Dozier, J., 1996. A generalized split-window algorithm for retrieving landsurface temperature from space. IEEE Transactions on Geoscience and Remote Sensing 34, $892-905$.

Wan, Z., Li, Z.-L., 1997. A physics-based algorithm for retrieving land-surface emissivity and temperature from EOS/MODIS data. IEEE Transactions on Geoscience and Remote Sensing 35, 980-996.

Wanner, W., Li, X., Strahler, A., 1995. On the derivation of kernels for kerneldriven models of bidirectional reflectance. Journal of Geophysical Research 100, 21077-21089.

Watson, K., 1992. Two-temperature method for measuring emissivity. Remote Sensing of Environment 42, 117-121.

Weiss, M., Jacob, F., Baret, F., Pragnère, A., Bruchou, C., Leroy, M., Hautecoeur, O., Prévot, L., Bruguier, N., 2002. Evaluation of kernel-driven BRDF models for the normalization of Alpilles/ReSeDA PolDER data. Agronomie: Agriculture and Environment 22, 531-536.

Xiong, X., Chiang, K., Guenther, B., Barnes, W., 2002. MODIS Thermal Emissive Bands Calibration Algorithm and On-orbit Performance. In: Proceedings of SPIE - Optical Remote Sensing of the Atmosphere and Clouds III.

Yamaguchi, Y., Kahle, A., Tsu, H., Kawakami, T., Pniel, M., 1998. Overview of Advanced Space-borne Thermal Emission and Reflection Radiometer (ASTER). IEEE Transactions on Geoscience and Remote Sensing 36, 1282-1289.

Zhou, L., Dickinson, R., Ogawa, K., Tian, Y., Jin, M., Schmugge, T., 2003. Relations between albedos and emissivities from MODIS and ASTER data over North African Desert. Geophysical Research Letters 30, 2026-2029. 


\section{List of Figures}

1 Illustration of the sensor spectral response functions (solid lines) and the corresponding channel averaged wavelengths (dashed lines), over the TIR domain for both ASTER (first subplot, channels numbered 10 to 14) and MODIS (second subplot, channels numbered 29 to 32). The example of atmospheric transmittance spectrum (third subplot) was simulated using MODTRAN 4 along with one of the atmospheric profiles used in this study (see $\S 2.3 .2$ ), when considering a nadir view angle.

2 Flowchart of the TISIE algorithm used to derived MIR and TIR emissivities when considering anyone of the MODIS MIR channels $(20,22$ or 23$)$ and the MODIS TIR channel 31 to compute the TISIE (from Petitcolin and Vermote (2002)).

3 Scatterplots of MODIS and ASTER Top Of Atmosphere (TOA) Brightness Temperatures (BT) for both the Africa and Jornada scenes. The solid line is the 1:1 line.

4 Scatterplots of MODIS and ASTER Surface Brightness Temperature (SBT) for both the Africa and Jornada scenes. The solid line is the $1: 1$ line.

5 Scatterplots of MODIS and ASTER surface emissivity estimates for both the Africa and Jornada scenes. The solid line is the 1:1 line. For a better display, the axis range between 0.8 and 1 , and 0.9 and 1, when considering the ASTER / MODIS bands 29/11, and bands $31 / 13$ and $31 / 14$, respectively.

6 Scatterplots of MODIS and ASTER Surface Radiometric Temperatures (SRT) estimates for both the Africa and Jornada scenes. The solid line is the $1: 1$ line. 

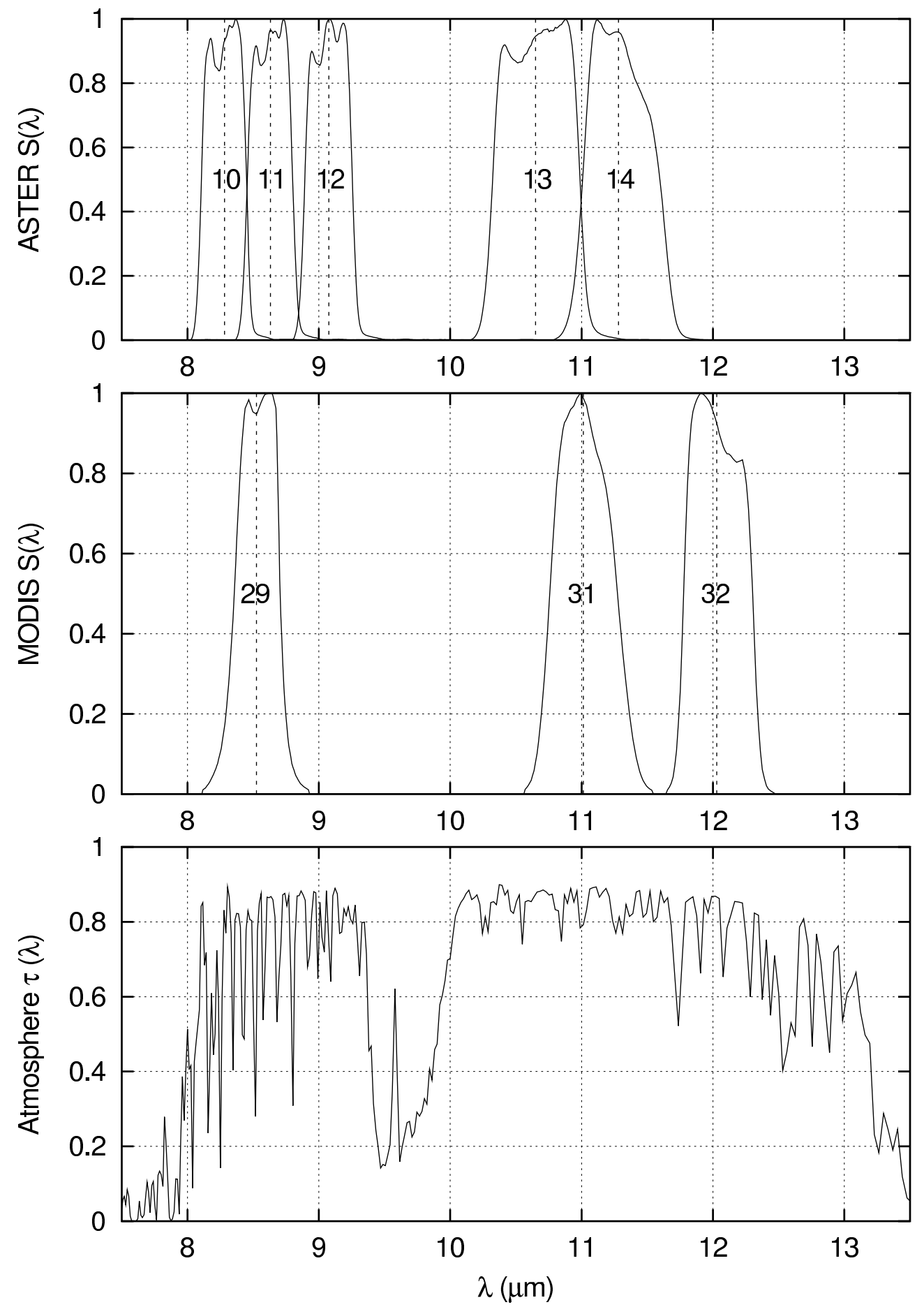

Fig. 1. Illustration of the sensor spectral response functions (solid lines) and the corresponding channel averaged wavelengths (dashed lines), over the TIR domain for both ASTER (first subplot, channels numbered 10 to 14) and MODIS (second subplot, channels numbered 29 to 32). The example of atmospheric transmittance spectrum (third subplot) was simulated using MODTRAN 4 along with one of the atmospheric profiles used in this study (see $§ 2.3 .2$ ), when considering a nadir view angle. 


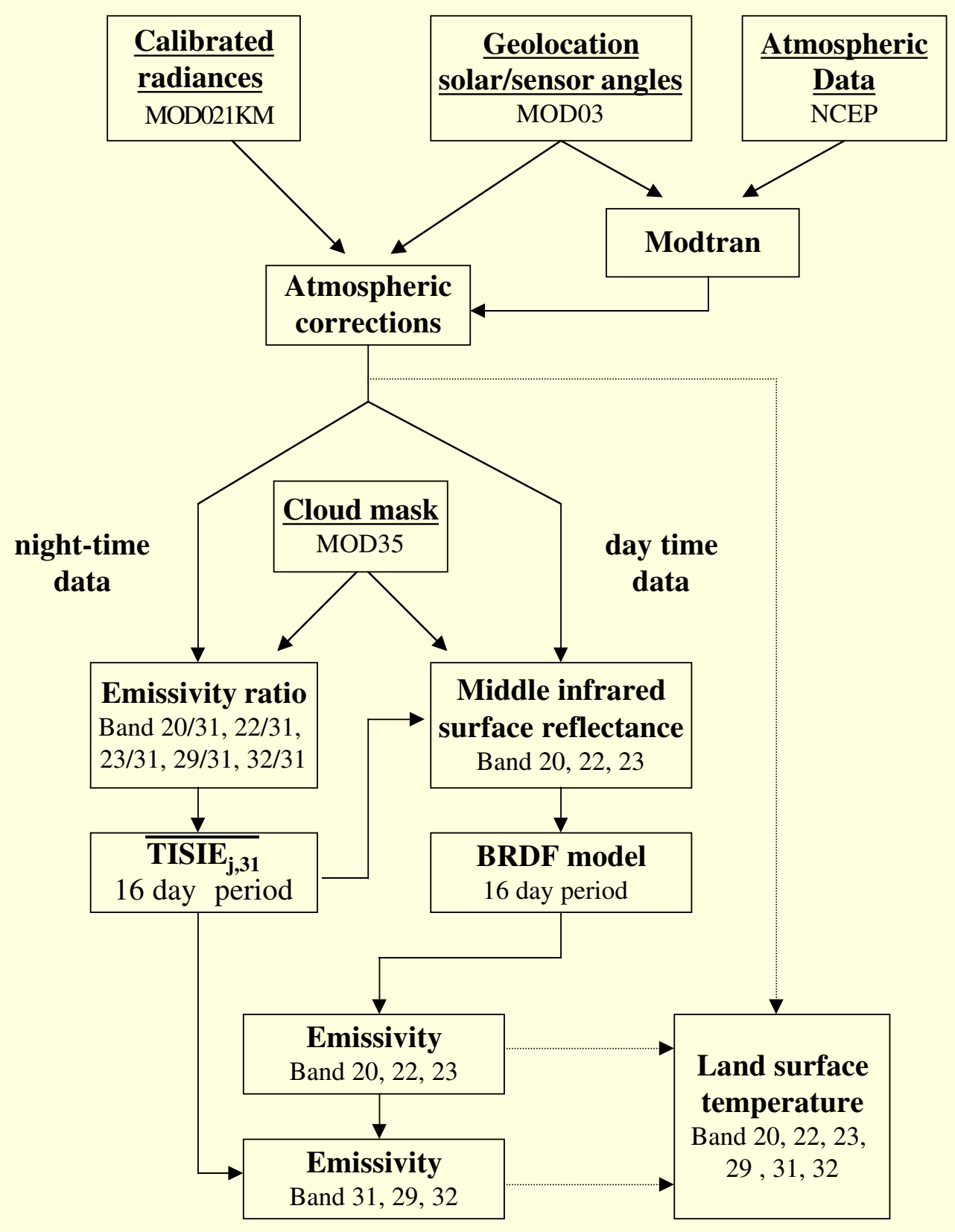

Fig. 2. Flowchart of the TISIE algorithm used to derived MIR and TIR emissivities when considering anyone of the MODIS MIR channels (20,22 or 23) and the MODIS TIR channel 31 to compute the TISIE (from Petitcolin and Vermote (2002)). 

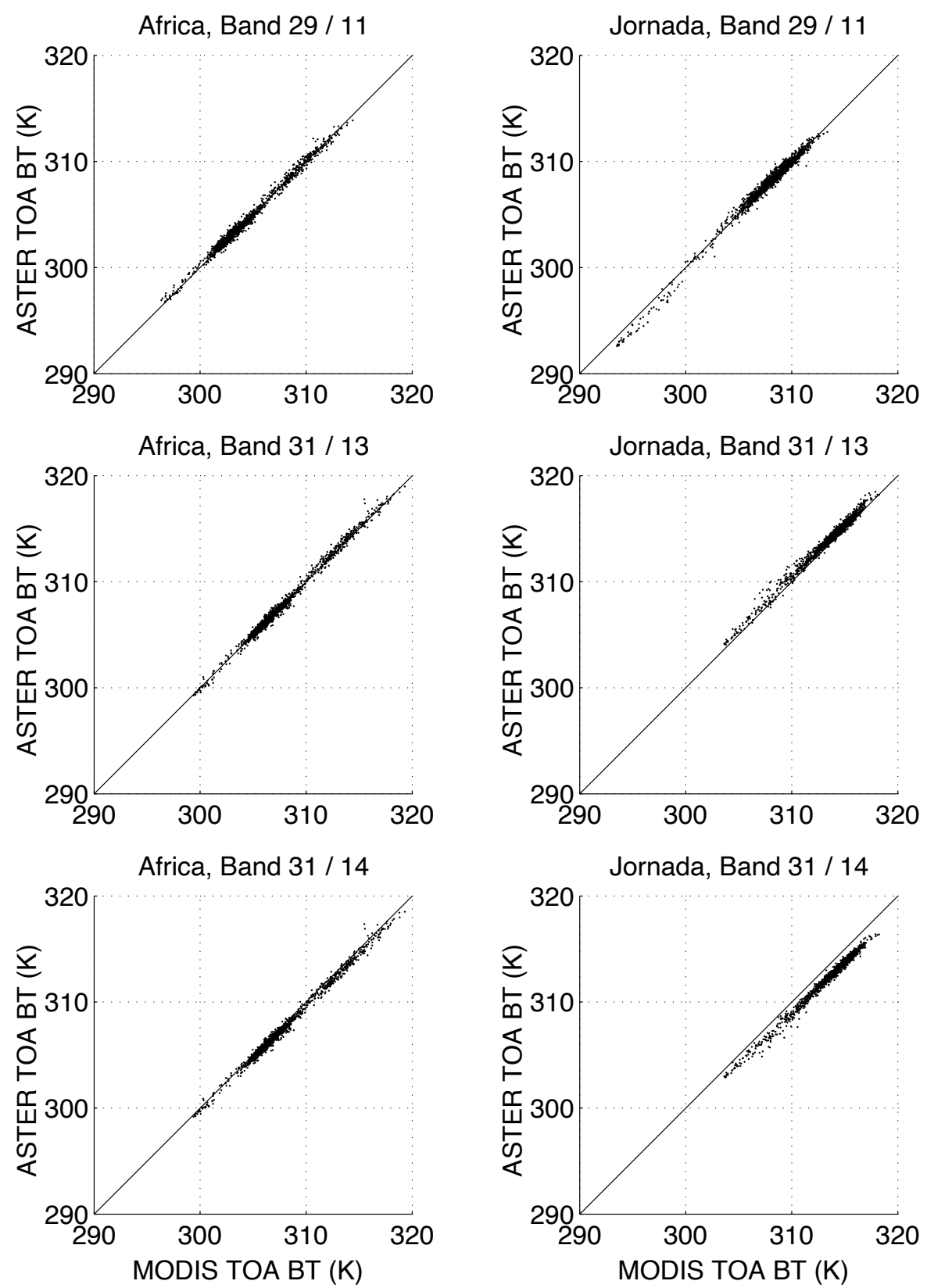

Fig. 3. Scatterplots of MODIS and ASTER Top Of Atmosphere (TOA) Brightness Temperatures (BT) for both the Africa and Jornada scenes. The solid line is the 1:1 line. 

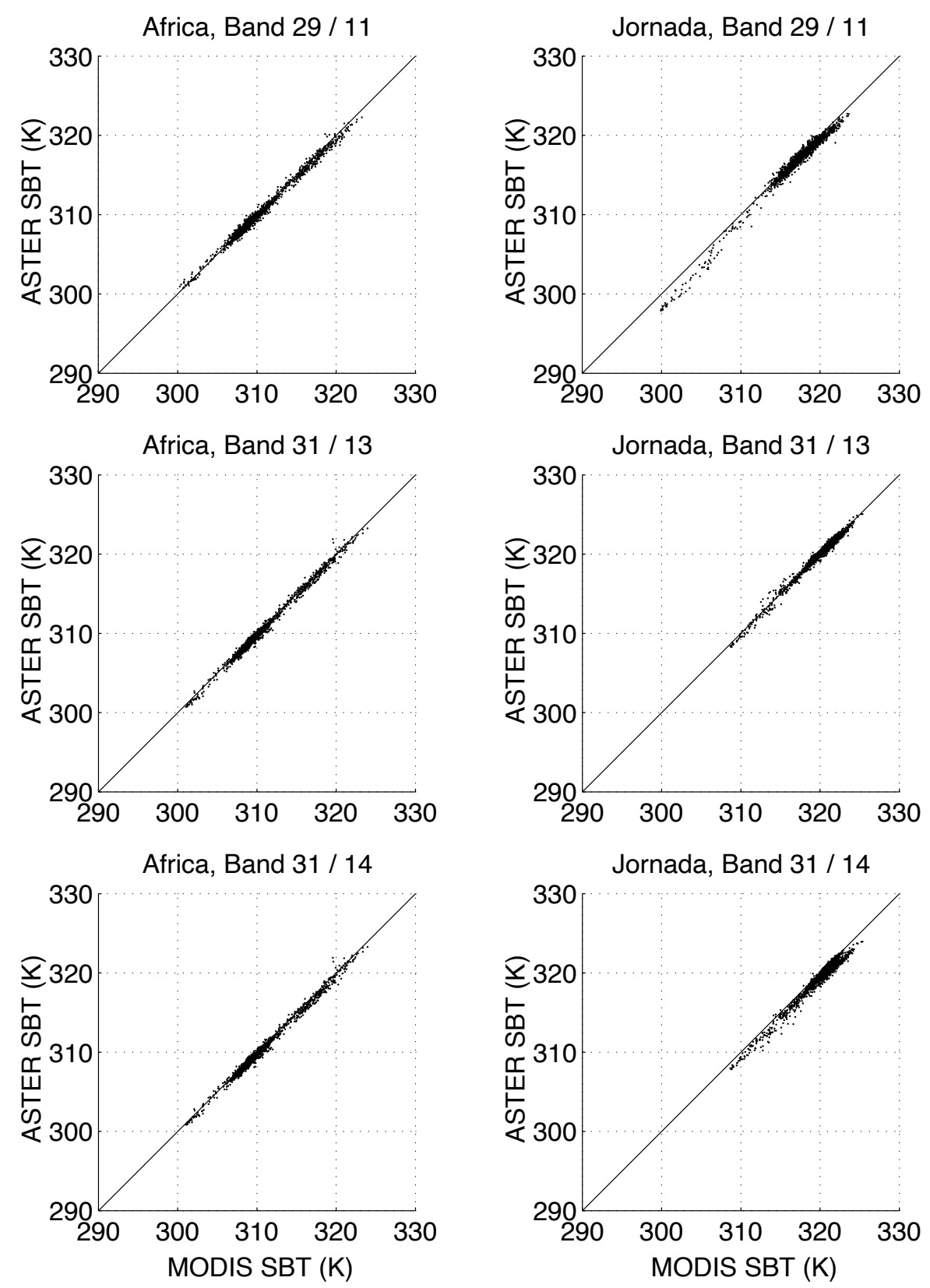

Fig. 4. Scatterplots of MODIS and ASTER Surface Brightness Temperature (SBT) for both the Africa and Jornada scenes. The solid line is the 1:1 line. 

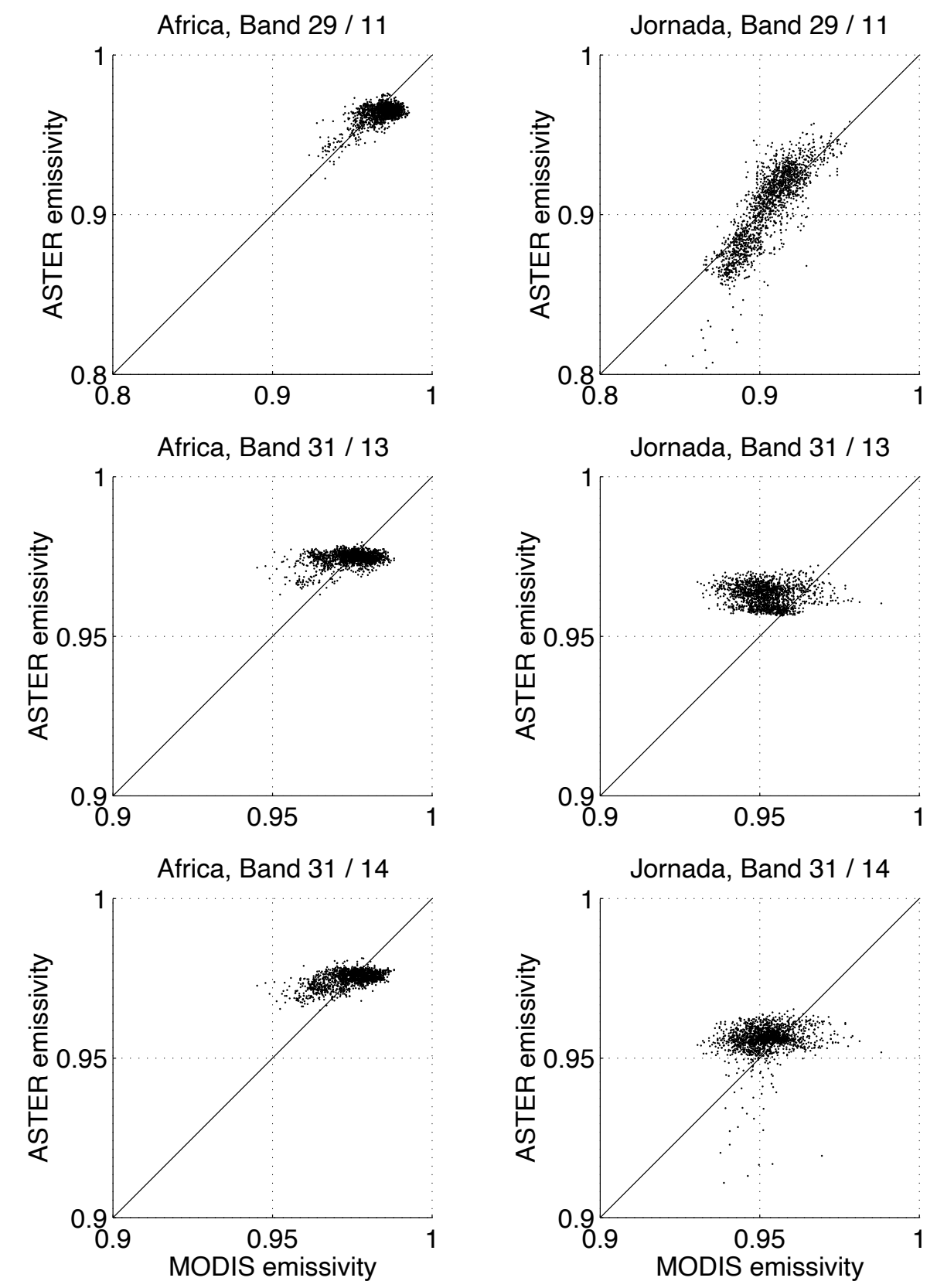

Fig. 5. Scatterplots of MODIS and ASTER surface emissivity estimates for both the Africa and Jornada scenes. The solid line is the 1:1 line. For a better display, the axis range between 0.8 and 1, and 0.9 and 1, when considering the ASTER / MODIS bands 29 / 11, and bands $31 / 13$ and $31 / 14$, respectively. 

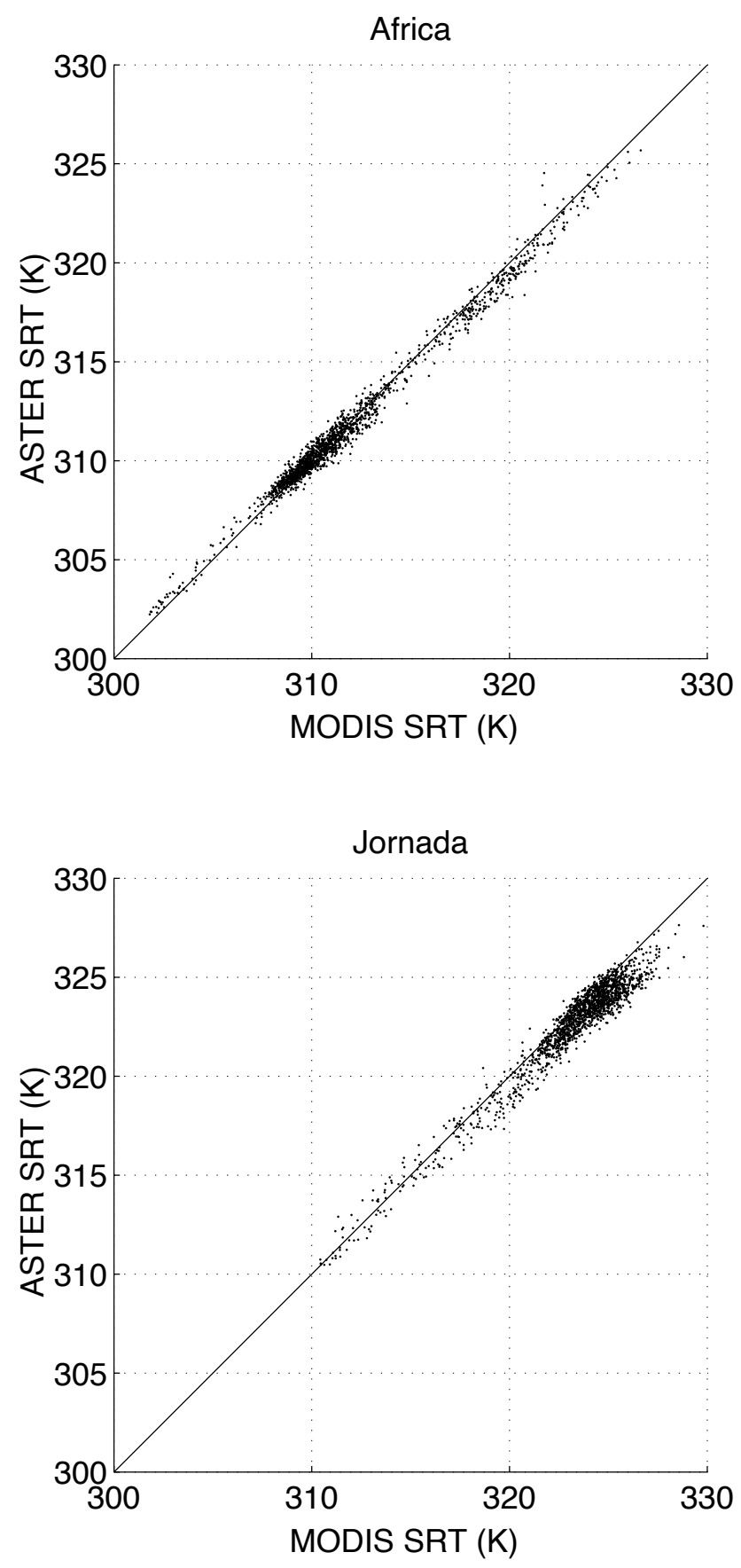

Fig. 6. Scatterplots of MODIS and ASTER Surface Radiometric Temperatures (SRT) estimates for both the Africa and Jornada scenes. The solid line is the 1:1 line. 


\section{List of Tables}

1 Numerical values of waveband averaged atmospheric transmittance $\tau_{a}$ over ASTER (top) and MODIS (bottom) channels, when considering the atmospheric transmittance spectra displayed in Figure 1. The gray cells correspond to the intercompared ASTER / MODIS channels, i.e. 11 / 29, 13 / 31, 14 / 31 .

2 Values of atmospheric Water Vapor Content (WVC) estimated from the four NCEP profiles used to process the MODIS data and surrounding the ASTER scenes. The profile the closest to the ASTER scene amongst these four was used to atmospherically correct the ASTER data. Numbers between parenthesis correspond to the latitude and longitude of the profiles.

3 Comparison between MODIS and ASTER top of atmosphere (TOA) brightness temperatures over both Africa and the Jornada. St. dev. means the standard deviation of the ASTER aggregated values inside the MODIS pixels for the considered channel.

4 Comparison between MODIS and ASTER Surface Brightness Temperatures (SBT) over both Africa and the Jornada. St. dev. means the standard deviation of brightness temperature of the ASTER aggregated values inside the MODIS pixels for the considered channel. "Jornada Adjusted (respectively Shifted) NCEP for ASTER" means the comparison results when considering the ASTER Jornada scene atmospherically corrected by using the NCEP profile adjusted for surface temperature and humidity conditions (respectively the NCEP profile with a shifted humidity profile).

5 Comparison between MODIS and ASTER emissivity estimates over both Africa and the Jornada. St. dev. means the standard deviation of emissivity of the ASTER aggregated values inside the MODIS pixels for the considered channel.

6 Comparison between MODIS and ASTER Surface Radiometric Temperatures (SRT) estimates over both Africa and the Jornada. St. dev. means the standard deviation of radiometric temperature of the ASTER aggregated values inside the MODIS pixels. 
7 Comparison between MODIS and ASTER radiometric temperatures for different level of variability of the ASTER aggregated values inside MODIS pixels. St. dev. means the standard deviation of radiometric temperature of the ASTER aggregated values. Pix. numb means the number of selected pixels for the comparison, after the removal of the ASTER aggregated values that corresponded to a st. dev larger than the threshold value. 


\begin{tabular}{c|cccccccc}
\hline \multicolumn{7}{c}{ ASTER } \\
\hline Bands & 10 & & 11 & 12 & 13 & & 14 & \\
$\tau_{a}$ & 0.6697 & & 0.7560 & 0.8144 & 0.8462 & & 0.8252 & \\
\hline \multicolumn{7}{c}{ MODIS } \\
\hline Bands & & 29 & & & 31 & & 32 \\
$\tau_{a}$ & & 0.7398 & & 0.8353 & 0.7827
\end{tabular}

Table 1

Numerical values of waveband averaged atmospheric transmittance $\tau_{a}$ over ASTER (top) and MODIS (bottom) channels, when considering the atmospheric transmittance spectra displayed in Figure 1. The gray cells correspond to the intercompared ASTER / MODIS channels, i.e. 11 / 29, 13 / 31, 14 / 31 . 
Table 2

\begin{tabular}{|c|c|c|}
\hline $\begin{array}{l}\text { Sensor } \\
\& \text { scene }\end{array}$ & Profile & 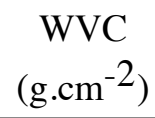 \\
\hline \multirow{6}{*}{$\begin{array}{c}\text { MODIS } \\
\text { Africa }\end{array}$} & Raw NCEP $\left(\mathrm{N} 09^{\circ}, \mathrm{E} 021^{\circ}\right)$ & 1.63 \\
\hline & Raw NCEP $\left(\mathrm{N} 09^{\circ}, \mathrm{E} 022^{\circ}\right)$ & 1.70 \\
\hline & $\operatorname{Raw} \operatorname{NCEP}\left(\mathrm{N} 10^{\circ}, \mathrm{E} 021^{\circ}\right)$ & 1.54 \\
\hline & $\operatorname{Raw} \operatorname{NCEP}\left(\mathrm{N} 10^{\circ}, \mathrm{E} 022^{\circ}\right)$ & 1.58 \\
\hline & Mean value & 1.61 \\
\hline & Max - Min & 0.16 \\
\hline $\begin{array}{c}\text { ASTER } \\
\text { Africa }\end{array}$ & Raw NCEP $\left(\mathrm{N} 10^{\circ}, \mathrm{E} 022^{\circ}\right)$ & 1.58 \\
\hline \multirow{6}{*}{$\begin{array}{c}\text { MODIS } \\
\text { Jornada }\end{array}$} & Raw $\operatorname{NCEP}\left(\mathrm{N} 32^{\circ}, \mathrm{W} 106^{\circ}\right)$ & 2.19 \\
\hline & $\operatorname{Raw} \operatorname{NCEP}\left(\mathrm{N} 32^{\circ}, \mathrm{W} 107^{\circ}\right)$ & 1.92 \\
\hline & $\operatorname{Raw} \operatorname{NCEP}\left(\mathrm{N} 33^{\circ}, \mathrm{W} 106^{\circ}\right)$ & 2.06 \\
\hline & $\operatorname{Raw} \operatorname{NCEP}\left(\mathrm{N} 33^{\circ}, \mathrm{W} 107^{\circ}\right)$ & 1.77 \\
\hline & Mean value & 1.98 \\
\hline & Max - Min & 0.41 \\
\hline ASTER & Raw NCEP $\left(\mathrm{N} 33^{\circ}, \mathrm{W} 107^{\circ}\right)$ & 1.77 \\
\hline Jornada & Adjusted NCEP & 1.89 \\
\hline
\end{tabular}

Values of atmospheric Water Vapor Content (WVC) estimated from the four NCEP profiles used to process the MODIS data and surrounding the ASTER scenes. The profile the closest to the ASTER scene amongst these four was used to atmospherically correct the ASTER data. Numbers between parenthesis correspond to the latitude and longitude of the profiles. 
Table 3

\begin{tabular}{c|c|c|c|c}
\multicolumn{3}{c}{} & \multicolumn{3}{c}{ MODIS / ASTER bands } \\
Scene & & $29 / 11$ & $31 / 13$ & $31 / 14$ \\
\hline \multirow{4}{*}{ Africa } & RMSD (K) & 0.29 & 0.28 & 0.42 \\
& bias (K) & -0.05 & -0.03 & 0.32 \\
& st. dev. (K) & 1.08 & 1.19 & 1.14 \\
\hline \multirow{4}{*}{ Jornada } & RMSD (K) & 0.36 & 0.48 & 1.22 \\
& bias (K) & -0.06 & -0.39 & 1.20 \\
& st. dev. (K) & 1.03 & 0.99 & 0.99
\end{tabular}

Comparison between MODIS and ASTER top of atmosphere (TOA) brightness temperatures over both Africa and the Jornada. St. dev. means the standard deviation of the ASTER aggregated values inside the MODIS pixels for the considered channel. 
Table 4

\begin{tabular}{|c|c|c|c|c|}
\hline \multirow{2}{*}{ Scene } & & \multicolumn{3}{|c|}{ MODIS / ASTER bands } \\
\hline & & $29 / 11$ & $31 / 13$ & $31 / 14$ \\
\hline \multirow{3}{*}{ Africa } & $\operatorname{RMSD}(\mathrm{K})$ & 0.42 & 0.43 & 0.46 \\
\hline & bias (K) & 0.19 & 0.29 & 0.33 \\
\hline & st. dev. (K) & 1.36 & 1.36 & 1.32 \\
\hline \multirow{3}{*}{ Jornada } & $\operatorname{RMSD}(\mathrm{K})$ & 1.02 & 0.72 & 1.43 \\
\hline & bias $(\mathrm{K})$ & 0.89 & 0.62 & 1.35 \\
\hline & st. dev. (K) & 1.24 & 1.13 & 1.15 \\
\hline Jornada & $\operatorname{RMSD}(\mathrm{K})$ & 0.87 & 0.54 & 1.22 \\
\hline Adjusted NCEP & bias $(\mathrm{K})$ & 0.72 & 0.41 & 1.12 \\
\hline for ASTER & st. dev. (K) & 1.25 & 1.14 & 1.16 \\
\hline Jornada & $\operatorname{RMSD}(\mathrm{K})$ & 0.57 & 0.15 & 0.73 \\
\hline Shifted NCEP & bias $(\mathrm{K})$ & 0.41 & 0.01 & 0.63 \\
\hline for ASTER & st. dev. (K) & 1.25 & 1.14 & 1.17 \\
\hline
\end{tabular}

Comparison between MODIS and ASTER Surface Brightness Temperatures (SBT) over both Africa and the Jornada. St. dev. means the standard deviation of brightness temperature of the ASTER aggregated values inside the MODIS pixels for the considered channel. "Jornada Adjusted (respectively Shifted) NCEP for ASTER" means the comparison results when considering the ASTER Jornada scene atmospherically corrected by using the NCEP profile adjusted for surface temperature and humidity conditions (respectively the NCEP profile with a shifted humidity profile). 
Table 5

\begin{tabular}{|c|c|c|c|c|}
\hline \multirow{2}{*}{ Scene } & & \multicolumn{3}{|c|}{ MODIS / ASTER bands } \\
\hline & & $29 / 11$ & $31 / 13$ & $31 / 14$ \\
\hline \multirow{3}{*}{ Africa } & RMSD & 0.009 & 0.006 & 0.006 \\
\hline & bias & 0.005 & 0.0001 & -0.0004 \\
\hline & st. dev. & 0.009 & 0.004 & 0.004 \\
\hline \multirow{3}{*}{ Jornada } & RMSD & 0.016 & 0.014 & 0.008 \\
\hline & bias & 0.002 & -0.011 & -0.004 \\
\hline & st. dev. & 0.012 & 0.002 & 0.003 \\
\hline
\end{tabular}

Comparison between MODIS and ASTER emissivity estimates over both Africa and the Jornada. St. dev. means the standard deviation of emissivity of the ASTER aggregated values inside the MODIS pixels for the considered channel. 
Table 6

\begin{tabular}{c|c|c} 
Scene & & SRT \\
\hline \multirow{4}{*}{ Africa } & RMSD (K) & 0.50 \\
& bias (K) & 0.06 \\
& st. dev. (K) & 1.41 \\
\hline \multirow{3}{*}{ Jornada } & RMSD (K) & 0.86 \\
& bias (K) & 0.67 \\
& st. dev. (K) & 1.19
\end{tabular}

Comparison between MODIS and ASTER Surface Radiometric Temperatures (SRT) estimates over both Africa and the Jornada. St. dev. means the standard deviation of radiometric temperature of the ASTER aggregated values inside the MODIS pixels. 
Table 7

\begin{tabular}{c|c|cc}
$\begin{array}{c}\text { Filter } \\
\text { threshold } \\
\text { value }\end{array}$ & & Africa & Jornada \\
\hline \multirow{3}{*}{$2.5 \mathrm{~K}$} & pix. numb. & 1661 & 1662 \\
& RMSD (K) & 0.50 & 0.92 \\
& bias (K) & 0.06 & 0.64 \\
& st. dev. (K) & 1.41 & 1.16 \\
\hline \multirow{3}{*}{$1 \mathrm{~K}$} & pix. numb. & 548 & 887 \\
& RMSD (K) & 0.37 & 0.86 \\
& bias (K) & -0.04 & 0.60 \\
& st. dev. (K) & 0.75 & 0.77 \\
\hline \multirow{3}{*}{$0.5 \mathrm{~K}$} & pix. numb. & 38 & 46 \\
& RMSD (K) & 0.34 & 0.66 \\
& bias (K) & -0.11 & 0.21 \\
& st. dev. (K) & 0.44 & 0.44
\end{tabular}

Comparison between MODIS and ASTER radiometric temperatures for different level of variability of the ASTER aggregated values inside MODIS pixels. St. dev. means the standard deviation of radiometric temperature of the ASTER aggregated values. Pix. numb means the number of selected pixels for the comparison, after the removal of the ASTER aggregated values that corresponded to a st. dev larger than the threshold value. 
Toulouse, November, 23, 2003

Dear Dr. Bauer,

Please find enclosed 1 copy of the revised manuscript RSE-D-03-00285 for publication in Remote Sensing of Environment:

Comparison of land surface emissivity and radiometric temperature derived from MODIS and ASTER sensors

The manuscript was changed according to most of the reviewer comments. The way we accounted for these comments, as well as the reasons we did not consider some of them are discussed in the replies on next pages. For the benefit of the reader, we added a table of content which will be removed after final acceptation.

Best Regards,

Frédéric JACOB

Département Sciences et Méthodes

Laboratoire de Télédétection et Gestion des Territoires

75 voie du TOEC

31076 TOULOUSE Cedex 3 FRANCE

Phone: 33(0)5-61-15-29-61

Fax: 33(0)5-61-15-30-60

email: frederic.jacob@esa-purpan.fr 


\section{Replies to reviewer \#1}

$\underline{\text { Summary }}$

According to the suggestion of the reviewer, repetitions were removed, as well as the Appendix. However, it was difficult to substantially reduce the size of the manuscript. Indeed, it seems that the complexity of the TISIE method, the fundamental differences between the compared algorithms, the utility of performing such a comparison, and the strategy used for atmospheric corrections led reviewers to ask for more explanations. Therefore, we had to give more details about:

- the sources of discrepancies between the algorithms because of their fundamental differences on both the assumptions and underlaying physics (January review / Appreciation and Specific comments / Multiple occurrences / 4),

- the interest of comparing algorithms as complementary investigations to validation studies (January review / General comments / 1 and October review / Reviewer 1 / comment 1 ),

- the interest of the study for further investigations such as 1) upscaling issues and 2) the ASTER result extension to the global scale provided by MODIS, mentioned now in the conclusion (January review / General comments / 1),

- the description of the TISIE algorithm (January review / General comments / 4) by giving enough information such as the Appendix is unnecessary (October Review / Reviewer 1 / Summary),

- the definition of upscaling processes (January review / Specific comments / Single occurrence / 4),

- the table of numerical values of atmospheric transmittance for the different ASTER and MODIS channels, and its analysis (January review / Specific comments / Single occurrence / 5),

- the expected accuracies of both the MODIS / ASTER at sensor level brightness temperatures and the algorithms, given by previous studies (October review / 
Reviewer 1 / summary),

- the previous studies that analyzed the assumptions the algorithms relied on, especially the change in land status that does not affect dramatically both TISIE and MIR BRDF (October review / Reviewer 1 / summary),

- the low correlation between emissivity retrievals at $11 \mu \mathrm{m}$ and the possibility to have reach in this case algorithm limitations (October review / Reviewer 1 / comment 4),

- the listing in Conclusion of the errors for each step of the procedure used to go from brightness temperature at the sensor level to the emissivity and surface radiometric temperature retrievals (October review / Reviewer 1 / comment 6),

- the discussion about the spatial interpolation of the atmosphere radiative variables for the processing of the MODIS data (October review / Reviewer 3 / comment for P17 / L10-14),

- and the necessity to assess the performances of the atmospheric corrections before dealing with the algorithm comparison over a larger database in order to draw a general conclusion at the global scale (October review / Reviewer 3 / last comment).

The comparison results are not reported anymore to four decimal places of accuracy. According to the scientific literature (Schmugge et al., 1998a; Nerry et al., 1998; Petitcolin et al., 2002a,b; Petitcolin and Vermote, 2002), the tables give now values with 4 decimal places for atmospheric transmittance, 2 decimal places for both atmospheric water vapor content and temperature, and 3 decimal places for emissivity. Besides, in order to consider the error characteristics of both data and modeling, we also added the following information. The MODIS and ASTER products we used in this study (i.e. brightness temperature at the sensor level), as well as the TES and TISIE algorithms, are now presented by giving their expected accuracies. For this, we considered results reported by previous studies based on either sensitivity analysis or validation studies. Moreover, the comparison results we obtained for both intermediary variables (surface brightness temperature at the sensor level) and algorithm 
retrievals (surface emissivity and radiometric temperature) are now confronted to the theoretical accuracies of both sensors and algorithms.

$\underline{\text { Comment (1) }}$

The reviewer claimed that not considering reference, e.g. non satellite-based data, it is difficult to judge how well the retrieval schemes are working. We partially agree with this statement. It is definitely necessary to perform validation studies that aim at ensuring the accuracies of the proposed models or algorithms. However, performing validation studies requires much effort when attempting to account for numerous land use and environmental situations. In this context, performing algorithm comparisons is a complementary solution that allows assessing the consistency between the algorithms when considering such numerous situations. This is clearly explained in Introduction, fourth paragraph. Besides, it was not claimed in Conclusion that the algorithms were validated. It was claimed that the consistency between the algorithms was verified, giving more confidence in the latter.

We want to mention to the reviewer that both TES and TISIE are presented in other papers, and that their comparison is unique. It was not our intention to quantitatively validate the emissivity and radiometric temperature values from either sensor or to validate the standard products, which for MODIS are only now being made available. This explains why we did not perform any comparison between the MODIS and ASTER standard products (see also the reply to reviewer comment \#3)

Atmospheric correction is obviously of prime interest when dealing with emissivity. It was explained in the submitted manuscript (P16/L10-13) "We decided to use the same information for both sensors in order to minimize the discrepancies between MODIS / TISIE and ASTER / TES estimates due to factors other than the algorithm differences". Since mentioning this when presenting the atmospheric correction strategy seemed not to be clear enough, it is now mentioned in the fifth paragraph of Introduction in the revised manuscript. 
Comment (2)

Methods based on the use of multidirectional information over optical domain generally characterize the angular distribution of the considered signals by considering 16 days temporal windows which correspond to the revisit of sun-synchronous satellites in the same observation configuration (Weiss and Baret, 1999; Privette et al., 1997; Schaaf et al., 2002; Petitcolin and Vermote, 2002). Therefore, the derived variables have a time meaning about 16 days. Such a standard approach is already used when generating official MODIS black sky and white sky albedo products, VEGETATION or PolDER official products. To account for this comment, we mentioned in the new version that the temporal windows were centered around the acquisition dates of nadir observations (see last paragraph of Section 2.2.1).

The scope of this study was to perform an algorithm comparison, not to discuss the algorithm validities. Besides, these were deeply analyzed and discussed in previous studies already mentioned in the manuscript. We did not claimed in the submitted version that the observed surfaces have not changed between acquisitions. It was claimed that TISIE relied on the assumption that changes in land surface status do not impact dramatically both TISIE and MIR BRDF (P12/L13-16). This was deeply analyzed in previous studies which showed that ratios of emissivity remain stable over several weeks (Petitcolin et al., 2002b), whereas inverting a BRDF KD model over measurements collected within a 16 day period provides a noise filter (Petitcolin and Vermote, 2002). Nevertheless, in the revised manuscript, we mentioned at the end of the section presenting the TISIE algorithm that the underlaying assumptions of the latter are discussed in details in the two references aforementioned. We also mention to the reviewer that methods based on the use of multidirectional information systematically rely on assuming the stability of the considered variables despite changes in land surface status. This is due to the temporal repetitivity of sun-synchronous satellites, and the resulting angular samplings of the considered signals.

We do not understand the possible link between the temperature profile inversion 
above arid surfaces during clear nights (which obviously drives changes in land surface temperature) and the stability of surface radiative properties such as narrowband or broadband land surface emissivity. Likewise, we do not understand a possible detection of such an inversion by the broadband emissivity. There is no assumption in the TISIE algorithm dealing with near surface temperature profile inversion. The latter drives the surface temperature as a result of surface energy balance, but does not drive surface radiative properties, which depend on soil radiative properties and humidity, vegetation radiative properties, and the amount of vegetation over soil. More explanations given by the reviewer would be appreciated.

Comment (3)

Indeed, the result of the comparison between the MODIS and ASTER standard products are not mentioned in the manuscript. Rather than a shame, it was a necessity to perform both atmospheric corrections and algorithm runs. Indeed, at the time we did this study, the official products (level 3) were not validated and therefore not available for comparison and publication. Besides, the TISIE algorithm applied to the MODIS data in this study is not that used to generate the official MODIS emissivity and radiometric temperature products. Thanks to the TERRA platform, the community can now use satellite data having a good instrumental quality, with new spectral, directional, spatial and temporal features. Therefore, one is free to use such good quality and original data for investigating the robustness of recent algorithms which differ from the official ones.

$\underline{\text { Comment (4) }}$

As mentioned by the reviewer, there is little correlation between the ASTER and MODIS - derived emissivities. We might have reached in this case the limits of either one of the algorithms or both of them. This was explained in the submitted manuscript (P26/L11-L19, and abstract). However, the comparison results for surface radiometric temperature retrievals were very good since they differ less than the 
0.8 - $1 \mathrm{~K}$ regularly quoted in literature as a requirement for many applications (see beginning of comments of reviewer \#3). Investigating a possible reach of the algorithm limits and understanding the low impact on surface radiometric temperature retrieval would require a deeper analysis of both algorithms which was out of the scope of this study. This is clearly mentioned in the new manuscript, end of the third paragraph of Section 3.3

Comment (5)

In the submitted manuscript, the Introduction mentioned that:

1) when dealing with surface energy balance model, an important parameter is surface temperature (P3/L4-6), which can be derived from TIR channel radiances using channel emissivities (P3/L11-12),

2) when dealing with Earth's radiation budget which is of prime interest for climate models, an important parameter is the broadband emissivity (P3/L6-8), which can be expressed as a linear combination of channel emissivities (P3/L12-14).

Since this paper focused on estimating channel emissivities, the references provided with these explanations are given for the benefit of the reader. These refereed studies explain in details the use of surface temperature for energy balance models (Schmugge et al., 1998b; Schmugge and Kustas, 1999; Olioso et al., 1999, 2002; Jacob et al., 2002), and the computation of broadband emissivity from spectral ones for climate models (Ogawa et al., 2003; Zhou et al., 2003). At the stage of the present study, we just assessed the accuracy of surface radiometric temperature and channel emissivities, and do not deal with applications.

Surface energy balance requires knowledge of surface temperature to derive sensible heat flux. It also requires knowledge of broadband emissivity to estimate surface radiative budget. A bad estimation of broadband emissivity is not a problem when dealing with day time surface net radiation since the resulting error is negligible. Indeed, daytime surface net radiation is mainly driven by its shortwave component. On the other hand, night time surface net radiation depends on its longwave component only and requires therefore an accurate estimation of broadband emissivity. However, 
there is at the present time numerous difficulties to estimate night time surface energy balance because of the difficulty to characterize well profile inversions over natural surfaces (Olioso, private communication). This induces that estimating broadband emissivity for such investigations is not of prime interest as compared to the challenge of modeling well profile inversions. Therefore, knowledge of surface spectral emissivity is currently important because it allows deriving 1) surface radiometric temperature which is key variable for sensible heat flux, and 2) broadband emissivity which is of prime interest for climate models. And this regardless of spatial resolution.

Comment (6)

This paper did not aim at performing an analysis of TES and TISIE algorithms, and therefore at theoretically analyzing performances at each stage of the retrieval schemes. This was already done by algorithm developers in previous studies: Becker and Li (1990); Li and Becker (1993); Nerry et al. (1998); Petitcolin et al. (2002a,b); Petitcolin and Vermote (2002) for TISIE, and Gillespie et al. (1996, 1998); Schmugge et al. (1998a, 2002) for TES. In our study, we had the possibility to assess the discrepancies between the MODIS and ASTER products at each stage of the processing, e.g. brightness temperature at the sensor level, surface brightness temperature after atmospheric corrections, and surface emissivity / radiometric temperature. In the submitted version, it was shown at the first stage of these comparisons (P20 - P22 when dealing with brightness temperature at the sensor level) that they were several coupled effects: surface emissivity, atmospheric transmittance, and sensor filter response functions. Even the cross-comparisons between the considered channels according to the atmospheric water vapor content did not allow emphasizing a clear correlation. When considering surface brightness temperature, it was shown that we had to reconsider atmospheric corrections to obtain MODIS and ASTER retrievals which agreed quite well. Besides, it was mentioned at the beginning of the section dealing with comparison of emissivity and radiometric temperature (Section 3.3 P25) that linking these comparison results with those previously obtained was difficult because 
of the different temporal meaning of the MODIS and ASTER retrievals. These points show that comparing experimentally the performances of the two retrieval schemes was difficult. A better way is therefore study analysis of each of these schemes, as previously done by the aforementioned studies. In order to be complement to these studies, we accounted for this comment by presenting in the revised version both data and algorithms with the corresponding accuracies reported by these studies, and confronting our comparison results with these accuracies. The MODIS and ASTER data are presented mentioning their expected accuracies (end of section 2.3.1). The TES and TISIE algorithms are presented both giving their expected accuracies (third paragraph of Introduction) and referring to studies dealing with algorithm analysis (end of last paragraph of Section 2.2.1 and last paragraph of Section 2.2.2). The results we obtained when comparing the ASTER and MODIS brightness temperature at the sensor level are now confronted with the sensor expected accuracies (end of Section 3.1), while the comparisons of the algorithm retrievals are given regarding expected accuracies of both algorithms (second paragraph of Section 3.3). Finally, a listing of the discrepancies between MODIS ans ASTER retrievals at each of the step of the retrieval schemes is given in Conclusion.

\section{Comment (7)}

The grammatical errors were corrected.

\section{Replies to reviewer \#3}

All suggestions were taken into account.

When dealing with the spatial interpolation of atmospheric radiative properties, we mention to the reviewer that bi-linear interpolation provides a fast and easy way to obtain continuous fields of atmospheric parameters. Indeed, at the scale of the ASTER scene $(63 \times 63 \mathrm{~km})$, we think that the NCEP atmospheric profiles follow a regular grid since no more than four of them are considered for the interpolation, (the four 
NCEP profiles surrounding the ASTER scene), and so do the interpolated atmospheric parameters. Nevertheless, we accounted for this interesting comment, and it is mentioned in the new manuscript that the remaining errors might result from an interpolation problem by mentioning the proposed reference (Section 3.2) .

We also added in last paragraph of Conclusion that drawing a general conclusion about the consistency between the algorithms would required a larger database and therefore much attention on the performances of atmospheric corrections at the global scale.

Rather than dealing with the MODIS "potential swath" (comment 7/19), we used "nominal swath".

\section{References}

Becker, F., Li, Z., 1990. Temperature Independent Spectral Indices in thermal infrared bands. Remote Sensing of Environment 32, 17-33.

Gillespie, A., Rokugawa, S., Hook, S., Matsunaga, T., Kahle, A., 1996. Temperature / emissivity separation algorithm. Theoretical basis document, version 2.1, NASA/GSFC, Greenbelt, MD, USA.

Gillespie, A., Rokugawa, S., Matsunaga, T., Cothern, S., Hook, S., Kahle, A., 1998. A temperature and emissivity separation algorithm for Advanced Spaceborne Thermal Emission and Reflection radiometer (ASTER) images. IEEE Transactions on Geoscience and Remote Sensing 36, 1113-126.

Jacob, F., Olioso, A., Gu, X., Su, Z., Seguin, B., 2002. Mapping surface fluxes using visible, near infrared, thermal infrared remote sensing data with a spatialized surface energy balance model. Agronomie: Agriculture and Environment 22,669680.

Li, Z.-L., Becker, F., 1993. Feasibility of land surface temperature and emissivity determination from AVHRR data. Remote Sensing of Environment 43, 67-85. 
Nerry, F., Peticolin, F., Stoll, M., 1998. Bidirectional reflectivity in AVHRR Channel 3: Application to a region in Northern Africa. Remote Sensing of Environment 66, $298-316$.

Ogawa, K., Schmugge, T., Jacob, F., French, A., 2003. Estimation of land surface window $(8-12 \mu \mathrm{m})$ emissivity from multi-spectral thermal infrared remote sensing - A case study in a part of Sahara Desert. Geophysical Research Letter 30, 10671071.

Olioso, A., Braud, I., Chanzy, A., Courault, D., Demarty, J., Kergoat, L., Lewan, L., Ottlé, C., Prévot, L., Zhao, W., Calvet, J., Cayrol, P., Jongschaap, R., Moulin, S., Noilhan, J., Wigneron, J.-P., 2002. SVAT modeling over the Alpilles-ReSeDA experiment: comparison of SVAT models, first results on wheat. Agronomie: Agriculture and Environment Submitted.

Olioso, A., Chauki, H., Courault, D., Wigneron, J., 1999. Estimation of evapotranspiration and photo-synthesis by assimilation of remote sensing data into SVAT models. Remote Sensing of Environment 68, 341-356.

Petitcolin, F., Nerry, F., Stoll, M.-P., 2002a. Mapping directional emissivity at $3.7 \mu \mathrm{m}$ using a simple model of bi-directional reflectivity. International Journal of Remote Sensing 23, 3443-3472.

Petitcolin, F., Nerry, F., Stoll, M.-P., 2002b. Mapping temperature independent spectral indice of emissivity and directional emissivity in avhrr channels 4 and 5. International Journal of Remote Sensing 23, 3473-3491.

Petitcolin, F., Vermote, E., 2002. Land surface reflectance, emissivity and temperature from MODIS middle and thermal infrared data. Remote Sensing of Environnement 83, 112-134.

Privette, J., Eck, T., Deering, D., 1997. Estimating spectral albedo and nadir reflectance through inversion of simple BRDF models with AVHRR/MODIS-like data. Journal of Geophysical Research 102, 29529-29542.

Schaaf, C., Gao, F., Strahler, A., Lucht, W., Li, X., Tsang, T., Strugnell, N., Zhang, X., Jin, Y., Muller, J.-P., Lewis, P., Barnsley, M., Hobson, P., Disney, M., Roberts, 
G., Dunderdale, M., Doll, C., D’Entremont, R., Hu, B., Liang, S., Privette, J., Roy, D., 2002. First operational BRDF, albedo nadir reflectance products from MODIS. Remote Sensing of Environment 83, 135-148.

Schmugge, T., French, A., Ritchie, J., Rango, A., Pelgrum, H., 2002. Temperature and emissivity separation from multispectral thermal infrared observations. Remote Sensing of Environment 79, 189-198.

Schmugge, T., Hook, S., Coll, C., 1998a. Recovering Surface Temperature and Emissivity from Thermal Infrared Multispectral Data. Remote Sensing of Environment $65,121-131$.

Schmugge, T., Kustas, W., 1999. Radiometry at infrared wavelengths for agricultural applications. Agronomie: Agriculture And Environment 19, 83-96.

Schmugge, T., Kustas, W., Humes, K., 1998b. Monitoring Land Surface Fluxes Using ASTER Observations. IEEE Transactions on Geoscience and Remote Sensing 36, $1421-1430$.

Weiss, M., Baret, F., 1999. Evaluation of Canopy Biophysical Variable Retrival Performances from the Accumulation of Large Swath Satellite Data. Remote Sensing of Environment 70, 293-306.

Zhou, L., Dickinson, R., Ogawa, K., Tian, Y., Jin, M., Schmugge, T., 2003. Relations between albedos and emissivities from MODIS and ASTER data over North African Desert. Geophysical Research Letters 30, 2026-2029. 